\title{
Análisis de los principales aspectos del Convenio para Evitar la Doble Imposición suscrito entre Colombia y Japón
}

\section{Analysis of the main aspects of the Double Taxation Convention concluded between Colombia and Japan}

\section{Análise dos principais aspectos do Acordo para evitar a dupla tributação assinado entre a Colômbia e o Japão}

\author{
Omar Sebastián Cabrera Cabrera ${ }^{1}$
}

\section{Resumen}

En diciembre de 2018, Colombia y Japón suscribieron un Convenio para Evitar la Doble Imposición, lo cual materializó el objetivo que en los últimos años ha tenido el país de lograr poseer una red extensa y robusta de tratados tributarios. Naturalmente, el tratado tributario con Japón se cimentó sobre la base del MOCDE en su versión más actualizada de
2017, que ya incluye las recomendaciones sugeridas por el plan de acción de BEPS. Sin embargo, al tratarse de un acuerdo bilateral en el que las partes pueden de manera libre negociar su contenido, existen varias disposiciones en el tratado que se apartan del MOCDE y sobre las cuales se hará un análisis. Asimismo, dada la reciente adhesión de Colombia a la OCDE, el país realizó una serie de reservas al Modelo de Convenio tributa-

\footnotetext{
${ }^{1}$ Abogado con profundización en Derecho Tributario y especialista en Derecho Económico Internacional de la Universidad Externado de Colombia. Especialista y magíster en Tributación de la Universidad de los Andes. Correo-e: omarcabreracabrera@ gmail.com DOI: https://doi.org/10.18601/16926722.n15.03
} 
rio de dicha organización internacional, las cuales serán contrastadas con el texto final del tratado suscrito con Japón.

Palabras clave: Convenio para Evitar la Doble Imposición suscrito entre Colombia y Japón, Tratado de adhesión de Colombia a la OCDE, Modelo de Convenio de la OCDE versión 2017 y plan de acción de BEPS de la OCDE.

\section{Abstract}

In December 2018, Colombia and Japan concluded a Double Taxation Convention that was in line with Colombia's aim of having an extensive network of tax treaties. Naturally, the tax treaty with Japan was drafted based on the OECD's tax model in its most updated version of 2017, which already includes the recommendations suggested by the BEPS action plan. However, since it is a bilateral agreement in which the parties can freely negotiate its content, there are several provisions in the treaty that deviate from the OECD's tax model and on which an analysis will be made. In addition, given Colombia's recent membership to the $\mathrm{OECD}$, the country established several reservations to the OECD tax model, which will be compared with the content of the treaty signed with Japan.

Keywords: Double Taxation Convention concluded between Colombia and Japan, Colombia's membership to the OECD, OECD's Model tax convention 2017 and OECD’s BEPS action plan.

\section{Resumo}

Em dezembro de 2018, a Colômbia e o Japão assinaram um Acordo para Evitar a
Dupla Tributação, que materializou o objetivo que o país teve nos últimos anos para alcançar uma extensa e robusta rede de tratados tributários. Naturalmente, o tratado fiscal com o Japão foi cimentado com base no MOCDE em sua versão mais atualizada de 2017, que já inclui as recomendações sugeridas pelo plano de ação do BEPS. No entanto, como é um acordo bilateral em que as partes podem negociar livremente seu conteúdo, existem várias disposições no tratado que se afastam do MOCDE e sobre as quais será feita uma análise. Além disso, dada a recente adesão da Colômbia à OCDE, o país fez uma série de reservas ao Acordo Modelo Tributário da referida organização internacional, que será contrastado com o texto final do tratado assinado com o Japão.

Palavras chave: Acordo para Evitar a Dupla Tributação assinado entre a Colômbia e o Japão, tratado de adesão da Colômbia à OCDE, Modelo da Convenção da OCDE versão 2017 e plano de ação da BEP da OCDE.

\section{Introducción}

El 19 de diciembre de 2018, en la ciudad de Tokio, Japón, los oficiales autorizados de los gobiernos de la República de Colombia y Japón suscribieron un Acuerdo para Evitar la Doble Imposición y prevenir la evasión y elusión tributaria (CDI); como mecanismo para profundizar y estrechar los lazos económicos y comerciales entre ambos países, lo cual culminó un proceso arduo de negociación llevado a cabo por ambas naciones.

Lo anterior teniendo en cuenta que Colombia, a partir de la firma de su primer CDI bilateral con España en 2005, inició una política pública de procurar el aumento de los flujos 
de inversión extranjera mediante la celebración de tratados tributarios con países estratégicos en temas de intercambio comercial y de inversión, en donde Japón era uno de los principales objetivos dada su importancia en términos económicos (Cabrera Cabrera, 2016; Mosquera, 2013, y Quiñones, 2012).

Sin embargo, a pesar de que el tratado tributario con Japón fue suscrito, el mismo no se encuentra a la fecha vigente en el país, toda vez que se requiere que Colombia lleve a feliz término todos los trámites internos legales y constitucionales para su adopción; al respecto, nos referimos puntualmente a la necesidad de incorporación del acuerdo mediante ley ${ }^{2}$, para su posterior control automático y previo de constitucionalidad que debe ser conducido por la Corte Constitucional $^{3}$, para así, proceder al instrumento diplomático del canje de notas (al ser este acuerdo de naturaleza bilateral $)^{4} \mathrm{y}$ culminar con la promulgación del decreto que adopta el tratado ${ }^{5}$ por parte del ejecutivo nacional.

Hechos los comentarios anteriores, es preciso señalar que el propósito de este texto se enmarca en la realización de un análisis conciso de los puntos más relevantes de dicho convenio tributario, no solo desde el estudio de las reglas distributivas allí contenidas, sino también desde sus normas especiales y demás contenido relevante para su funcionamiento y aplicación.
Adicionalmente, en el documento también se hará, en la medida de lo posible, un contraste comparativo de este convenio con la plantilla de Modelo de Convenio Tributario sobre la Renta y sobre el Patrimonio elaborado por la Organización para la Cooperación y el Desarrollo Económico (MOCDE), junto con algunas de las reservas realizadas por Colombia al MOCDE en su instrumento de adhesión al acuerdo constitutivo de la Organización para la Cooperación y el Desarrollo Económico (OCDE), el cual fue adoptado por el legislativo colombiano mediante la Ley 1950 de 2019.

En referencia a lo anterior, es importante hacer hincapié en que el MOCDE de 2017, el cual se tendrá como referencia para fines de este texto, se actualizó teniendo como norte y guía las principales conclusiones y recomendaciones de varias de las 15 acciones del plan Base Erosion and Profit Shifting (BEPS) de la OCDE, el cual, en términos completamente simples, pretendió revolucionar los principios existentes de la tributación internacional y de los convenios tributarios, teniendo en cuenta el contexto y la coyuntura actual, e incluso previó la modificación de los CDI bilaterales actualmente vigentes a través de un acuerdo multilateral (conocido como MLI por sus siglas en inglés).

Sin mayores preámbulos, se procederá a realizar y exponer los comentarios relevantes respecto de los que son, a nuestro juicio,

\footnotetext{
${ }^{2}$ Obligación establecida en el numeral 16) del artículo 150 de la Constitución Política de Colombia. ${ }^{3}$ Obligación reglada por el numeral 10) del artículo 241 de la Constitución Política de Colombia. ${ }^{4}$ Obligación contenida en el artículo 1 de la Ley 7 de 1944.

${ }^{5}$ Obligación contenida en el artículo 2 de la Ley 7 de 1944.
} 
los principales y más importantes artículos del CDI entre Colombia y Japón, sin dejar atrás que el artículo 29 de dicho tratado internacional señala que los títulos de los artículos se agregaron únicamente por comodidad de referencia y no afectarán la interpretación del convenio en conjunto.

\section{Título del tratado}

Partiendo de la órbita del Derecho Internacional Público, hay que poner de presente que los tratados internacionales, incluso los de índole tributaria, están antecedidos por un título, el cual, según el artículo 31 de la Convención de Viena sobre el Derecho de los Tratados de $1969^{[6]}$, hace parte del cuerpo del texto del acuerdo para fines de su interpretación.

A la luz de lo anterior, el título del CDI entre Colombia y Japón indica que se firma un

convenio entre la república de Colombia y Japón para la eliminación de la doble tributación con respecto a los impuestos sobre la renta y la prevención de la evasión y elusión tributarias.

En vista del título adoptado, puede evidenciarse como el ámbito de aplicación se está limitando exclusivamente a los "impuestos sobre la renta", dejando a un lado cualquier referencia a "impuestos sobre el capital o el patrimonio".

Con base en lo anterior, no fue la intención de las partes suscribientes el buscar la eliminación de la doble imposición que pueda surgir por la aplicación de impuestos sobre el patrimonio, razón por la que este CDI no incorpora las reglas del artículo 22 del MOCDE, el cual se refiere a las pautas para la imposición de impuestos al capital y/o al patrimonio que un residente de un Estado posea en el otro Estado.

Por lo tanto, el CDI entre Colombia y Japón no restringirá, por ejemplo, la facultad de Colombia de imponer a residentes fiscales colombianos impuestos a la riqueza o al patrimonio respecto de activos poseídos en el Japón, como lo puede ser, por ejemplo, un inmueble ubicado allí o acciones en entidades japonesas (algo que de todas maneras hubiese sido posible bajo el estándar genérico del numeral 4) del artículo 22 del MOCDE).

El inconveniente práctico que podría presentarse en el evento anterior es que en el caso en que hipotéticamente Japón impusiese de manera simultánea sobre esta riqueza localizada allí un impuesto similar, no habría forma de aliviar este doble gravamen, dado que el mecanismo para eliminar la doble imposición del CDI no aplica cuando la sobre tributación se derivada de impuestos al patrimonio (lo cual es sencillo de entender dado que la tributación del capital no fue regulada por este acuerdo).

Sin embargo, esta situación presunta e hipotética podría llevar a que Colombia y Japón evalúen iniciar trámites diplomáticos con la finalidad de hacer el ajuste respectivo al convenio y así evitar esta posible dificultad.

${ }^{6}$ Adoptada en Colombia mediante la Ley 32 de 1985. 
Asimismo, el CDI tampoco limita el derecho tributario de Colombia de someter a imposición bajo la figura del impuesto al patrimonio, activos que entidades residentes fiscales en Japón posean en el país (como, por ejemplo, el nuevo impuesto al patrimonio implementado por la Ley 1943 de 2018 y en cuyo espectro se encuentran entidades extranjeras que posean ciertos tipos de activos en el país como lo son, por nombrar alguno, obras de arte).

Ahora bien, respecto de este punto debe tenerse presente que, frente a la tributación de impuestos al patrimonio, Colombia en su adhesión a la OCDE se reservó el derecho de aplicar estas normas solo cuando exista reciprocidad, es decir, que en el otro Estado contratante haya, durante el respecto año gravable, un impuesto de similar naturaleza; sobre el particular, la Ley 1950 de 2019 indica:

Colombia también se reserva el derecho de limitar la aplicación de la Convención a impuestos sobre capital en la medida de que, durante el respectivo año fiscal, ambos Estados Contratantes impongan impuestos sobre el mismo capital o sobre los mismos elementos de capital.

De otro lado, el título del acuerdo con Japón también se refiere a la prevención de la elusión y la evasión fiscal, lo cual está actualizado conforme a los desarrollos del plan de BEPS de la OCDE. En ese sentido, consideramos que este título limitaría las oportunidades para armar e implementar estructuras de planeación fiscal no legítimas, dado que se debe interpretar el acuerdo con cadencia a su título, ya que este es una parte importante y relevante de la finalidad del acuerdo.

\section{Preámbulo del acuerdo}

Como primer punto, debe hacerse hincapié en que en el preámbulo del acuerdo se puede ver una clara influencia del MOCDE versión 2017, el cual debe decirse, adoptó al respecto la actualización sugerida por BEPS; hecha esta aclaración, dicho preámbulo establece lo siguiente:

La República de Colombia y Japón,

Deseando desarrollar aún más su relación económica y mejorar su cooperación en asuntos fiscales,

Con la intención de celebrar un convenio para eliminar la doble imposición con respecto a los impuestos sobre la renta sin crear oportunidades de no imposición o reducción de impuestos mediante evasión o elusión tributaria (incluida la práctica de la búsqueda del convenio más favorable -"treatyshopping"- que persigue la obtención de los beneficios previstos en este Convenio para el beneficio indirecto de residentes de terceros Estados).

En lo concerniente a lo anterior, es fundamental indicar que el parágrafo 72 de la acción 6 de BEPS, que buscaba contrarrestar la práctica abusiva de tratados, sugirió la actualización del preámbulo del MOCDE para hacer más amplio su ámbito de aplicación, y así establecer que la finalidad del acuerdo no solo estaba limitado a evitar la doble imposición, sino, también, atacar oportunidades de evasión o elusión fiscal, el treaty shopping (acceso no legítimo al acuerdo por la imposición de, por ejemplo, compañías plataforma o conduit companies) y la doble no imposición (Cabrera Cabrera, 2018a). 
Adicionalmente, el plan de acción de BEPS también sugería que todo preámbulo de un tratado tributario iniciara con el estándar de: "Deseando desarrollar aún más su relación económica y mejorar su cooperación en asuntos fiscales", toda vez que consideraba que era importante hacer énfasis en que el tratado también procura el estrechar las relaciones económicas en los Estados, dado que mucho se ha discutido respecto de si realmente la eliminación de barreras tributarias fomentan el flujo de operaciones bilaterales entre los Estados suscribientes, y además que estos CDI ayudan en la cooperación mutua en asuntos tributarios.

Así las cosas, puede verse cómo el CDI entre Colombia y Japón adopta a cabalidad estas sugerencias de la era BEPS.

\section{Personas cubiertas}

Al igual que el MOCDE, el artículo 1 del CDI limita el acceso subjetivo del tratado exclusivamente a aquellas personas que, según la legislación impositiva interna, sean consideradas como residentes fiscales de uno o de ambos países ${ }^{7}$.

Ahora bien, acogiendo las recomendaciones del plan BEPS en su acción 2 sobre el uso ilegítimo de entidades híbridas y la 6 sobre el abuso de tratados, como ya se mencionó, el segundo parágrafo del artículo 1 del CDI dispone que las rentas obtenidas por o a través de una entidad o acuerdo considerado como total o parcialmente transparente fiscalmente según la legislación tributaria de alguno de los Estados Contratantes, se considerarán rentas de un residente de uno de los Estados Contratante, pero solo si dichas rentas son tratadas, a efectos tributarios de ese Estado, como las rentas de un residente de dicho Estado Contratante ${ }^{8}$.

La última parte del artículo en mención establece la denominada saving clause agregada al MOCDE en 2017 (con una clara influencia del modelo de convenio fiscal de los Estados Unidos), en donde se indica expresamente que la aplicación del CDI no afectará la tributación que puede imponer alguno de los Estados a sus residentes, sin perjuicio de los beneficios otorgados en virtud del párrafo 3 del artículo 7, párrafo 2 del artículo 9 y los artículos $18,19,22,23,24$ y $27^{[9]}$.

\section{Impuestos cubiertos}

Respecto del ámbito de aplicación objetivo del CDI Colombia-Japón, es decir, frente a qué tipo de impuestos es aplicable esta convención tributaria, el artículo 2 de dicho acuerdo señala textualmente:

\footnotetext{
${ }^{7}$ Dicha norma del CDI señala lo siguiente: “Artículo 1 Personas Cubiertas 1. El presente Convenio se aplicará a las personas que residan en uno o en ambos Estados Contratantes".

${ }^{8}$ El numeral 2) del artículo 1 del CDI señala que: "Para los efectos del presente Convenio, las rentas obtenidas por o a través de una entidad o acuerdo que sea tratado como total o parcialmente transparente para efectos fiscales según la legislación tributaria de cualquiera de los Estados Contratantes se considerarán rentas de un residente de un Estado Contratante, pero solo en la medida en que las rentas sean tratadas, para los fines de tributación por ese Estado Contratante, como las rentas de un residente de ese Estado Contratante".

${ }^{9}$ El numeral 3) del artículo 1 del CDI señala: "El presente Convenio no afectará la tributación por un Estado Contratante frente a sus residentes, salvo con respecto a los beneficios otorgados en virtud del párrafo 3 del Artículo 7, párrafo 2 del Artículo 9 y los Artículos 18, 19, 22, 23, 24 y 27 ".
} 
El presente Convenio se aplicará a los impuestos sobre la renta exigibles en nombre de un Estado Contratante, independientemente de la forma en que se recauden.

Como se observa, en esta parte existe una desviación de gran importancia respecto de la redacción original del MOCDE, en la medida en que no se incluye la referencia a "impuestos que cobren subdivisiones políticas o sus entidades locales"; es decir, que en principio fue clara la voluntad de las partes de no buscar aplicar el CDI a impuestos que sean de propiedad de sus entidades territoriales, con lo cual sería obvio que, para el caso colombiano, el Impuesto de Industria y Comercio (ICA) no estará cubierto por el tratado ( $\sin$ entrar en detalles respecto de si el ICA puede considerarse como impuesto cubierto según la plantilla del MOCDE dado que es un tema que excede con creces el objetivo del texto). No obstante lo anterior, consideramos relevante mencionar que, para el caso de Japón, se incluyó como tributo cubierto por el CDI un impuesto local de sociedades (como se verá más adelante).

Así las cosas, esta redacción es concordante con la postura de Colombia en las reservas al MOCDE, dado que el país se reservó el derecho de no incluir tributos que sea de control de entidades descentralizadas o locales en dicha norma de "impuestos cubiertos". Sobre el particular, la reserva es la que se presenta a continuación:

Colombia se reserva el derecho de no incluir en el parágrafo 1, impuestos gravados en favor de subdivisiones políticas o autoridades locales.
Naturalmente, en línea con lo que se ha señalado previamente, tampoco se incluyó el impuesto al patrimonio y/o capital dentro de la lista del ámbito de aplicación objetivo del CDI.

Por su parte, el numeral 2 del CDI contempla la definición del término de "impuestos sobre la renta", la cual es idéntica a la establecida en el MOCDE versión 2017. En ese sentido, señala el tratado entre Colombia y Japón:

Se considerarán como impuestos sobre la renta, todos los impuestos que graven la totalidad de las rentas, o elementos de la renta, incluyendo los impuestos sobre las ganancias derivadas de la enajenación de cualquier propiedad, los impuestos sobre los montos totales de sueldos o salarios pagados por las empresas, al igual que los impuestos sobre las plusvalías.

Posteriormente, el numeral 3 del artículo en cuestión establece una lista, enunciativa más no taxativa como se verá, de los impuestos que serán cobijados por el acuerdo tomando en consideración el sistema tributario de cada Estado. En ese respecto, dicha norma señala:

3. Los impuestos existentes a los que se aplicará el presente Convenio son:

(a) en el caso de Colombia:

el impuesto sobre la renta y complementarios

(en lo sucesivo denominado el "impuesto colombiano"); y

(b) en el caso de Japón:

(i) el impuesto sobre la renta;

(ii) el impuesto sobre sociedades; 
(iii) el impuesto sobre la renta especial para la reconstrucción; y

(iv) el impuesto local de sociedades

(en lo sucesivo denominado el "impuesto japonés").

Para culminar el análisis de este artículo, el parágrafo 4 del mismo indica que el CDI también cubrirá cualquier impuesto que posteriormente sea implementado por cualquiera de los dos países, siempre que se trate de impuestos idénticos o sustancialmente similares a los impuestos antes listados, con lo cual puede afirmarse que el CDI no aplica exclusivamente a los impuestos de la lista, sino que también puede aplicar a impuestos que sean creados más adelante.

Asimismo, se dispone que para el caso anterior, las autoridades competentes procurarán notificar dicho cambio tributario, lo cual se deberá realizar por las vías allí establecidas $^{10}$.

\section{Definiciones}

El artículo 3 del CDI contiene las definiciones generales para fines de la aplicación e ilustración del tratado. En primera medida, se definen los términos de "Colombia"11 y
"Japón"12 , añadiendo que las referencias que se hagan a "un Estado Contratante" o "el otro Estado Contratante", significarán Colombia o Japón, según como lo requiera el contexto en cada caso concreto.

Posteriormente, se define el término "persona" como cualquier persona natural, sociedad o cualquier otro cuerpo de personas. Adicionalmente, se establece que el término "sociedad" significa personas jurídicas o cualquier otra entidad que se trate como persona jurídica para efectos tributarios.

Por su parte, se define el término "empresa" como el desarrollo de cualquier negocio y se indica que los términos "empresa de un Estado Contratante" y "empresa del otro Estado Contratante" significan, respectivamente, una empresa explotada por un residente de un Estado Contratante y una empresa explotada por un residente del otro Estado Contratante.

De otro lado, el término "autoridad competente" significa en Colombia, el Ministro de Hacienda y Crédito Público o su representante autorizado, y en Japón, el Ministro de Finanzas o su representante autorizado. Ahora bien, se define el término "nacional",

\footnotetext{
${ }^{10}$ El parágrafo 4 del artículo 2 del CDI señala: “4 4 El presente Convenio se aplicará también a los impuestos idénticos o sustancialmente similares que se impongan con posterioridad a la fecha de la firma del Convenio en adición a, o en lugar de, los impuestos existentes. Las autoridades competentes de los Estados Contratantes se notificarán entre sí cualquier cambio significativo que se haya introducido en su legislación tributaria".

${ }^{11}$ De acuerdo con el artículo 3 (1) (a) del CDI, "el término 'Colombia' significa la República de Colombia y, cuando se utiliza en un sentido geográfico, incluye su territorio, tanto continental como insular, su espacio aéreo, mar y áreas submarinas, y otros elementos sobre los que ejerce soberanía, derechos soberanos o jurisdicción en virtud de la Constitución colombiana de 1991 y sus leyes, y de conformidad con el derecho internacional, incluidos los tratados internacionales aplicables". ${ }^{12}$ De acuerdo con el artículo 3 (1) (b) del CDI, “el término 'Japón', cuando se utiliza en sentido geográfico, significa todo el territorio de Japón, incluido su mar territorial, en el que están vigentes las leyes relativas al impuesto japonés, y toda la zona más allá de su mar territorial, incluidos el fondo marino y el subsuelo del mismo, sobre el cual Japón tiene derechos soberanos de conformidad con el derecho internacional y en el que están vigentes las leyes relacionadas con el impuesto japonés".
} 
como: (i) cualquier persona que posea la nacionalidad o la ciudadanía de un Estado Contratante, y (ii) cualquier persona jurídica, sociedad de personas (partnership) o asociación que se considere así en virtud de las leyes en vigor en ese Estado Contratante.

También se define el término "tráfico internacional" como cualquier transporte realizado por una nave o aeronave, excepto cuando la nave o la aeronave sea operada únicamente entre lugares de un Estado Contratante y la empresa que opera la nave o la aeronave no es una empresa de ese Estado Contratante.

De la misma manera, también se establece la definición del concepto de "fondo de pensión", el cual es fundamental para la aplicación de varias reglas de distribución del $\mathrm{CDI}^{13}$, y que fue introducida en la actua- lización del MOCDE en 2017. Por su parte, debe tenerse presente que el protocolo del acuerdo trae también una definición del concepto de "fondo de pensión"14 y "fondo de cesantías" ${ }^{15}$ para la aplicación del tratado por parte de Colombia.

Por último, la parte final del artículo consagra la cláusula estándar de reenvío (renvoi clause) en su versión más actualizada del MOCDE 2017, en virtud de la cual para la aplicación del CDI en cualquier momento, cualquier término no definido expresamente en él, a menos que de su contexto se infiera una interpretación diferente o las autoridades competentes acuerden un significado diferente siguiendo el procedimiento amistoso, tendrá el significado que tenga en ese momento según la legislación interna de ese país, prevaleciendo siempre el significado de la legislación tributaria en caso de que

\footnotetext{
${ }^{13}$ De acuerdo con el CDI, "el término ‘fondo de pensiones reconocido' de un Estado Contratante significa una entidad o acuerdo establecido conforme a la ley de ese Estado Contratante que es tratado como una persona separada bajo las leyes tributarias de ese Estado Contratante y: (i) que se establece y opera exclusivamente o casi exclusivamente para administrar o proporcionar beneficios de jubilación y beneficios auxiliares o incidentales u otra remuneración similar a personas y que está regulado como tal por ese Estado Contratante o una de sus subdivisiones políticas o autoridades locales; o (ii) que se establece y opera exclusivamente o casi exclusivamente para invertir fondos en beneficio de otros fondos de pensiones reconocidos de ese Estado Contratante. Cuando una entidad o acuerdo establecido bajo la legislación de un Estado Contratante constituya un fondo de pensiones reconocido en virtud de la cláusula (i) o (ii) como si se tratara de una persona separada en virtud de la legislación tributaria de ese Estado Contratante, se considerará a los fines de este Convenio, como una persona independiente y será tratada como tal en virtud de la legislación tributaria de ese Estado Contratante y todos los activos y rentas de la entidad o acuerdo se tratarán como activos poseídos y rentas obtenidas por esa persona independiente y no por otra persona". ${ }^{14}$ El protocolo del CDI señala: "el término 'fondo de pensiones obligatorio' de Colombia significa un fondo regulado por la Ley 100 de 1993 y las disposiciones que la modifiquen o sustituyan, administrado o gestionado por las Sociedades Administradoras de Fondos de Pensiones y Cesantías que están sujetas a la vigilancia de la Superintendencia Financiera de Colombia y sujetas a las reglas previstas en la Parte 2 del Decreto 2555 de 2010".

${ }^{15}$ Según el protocolo del acuerdo: "el término 'fondo de cesantías' de Colombia significa un fondo que está: (i) regulado por la Ley 100 de 1993 y las disposiciones que la modifiquen o sustituyan; (ii) administrado o gestionado por las Administradoras de Fondos de Pensiones y Cesantías que están sujetas a la vigilancia de la Superintendencia Financiera de Colombia y están sujetas a las reglas establecidas en la Parte 2 del Decreto 2555 de 2010; (iii) creado para los efectos del Artículo 99 de la Ley 50 de 1990; y (iv) regulado en el Capítulo VIII de la Parte I del Estatuto Orgánico del Sistema Financiero".
} 
haya un conflicto de definición con otras legislaciones, como, por ejemplo, la civil o mercantil ${ }^{16}$.

\section{Residencia fiscal}

Mediante el artículo 4 del CDI se define el concepto de "residente fiscal", para lo cual se remite a las pautas generales del MOCDE. En ese respecto, se define a un "residente" como toda aquella persona que, por motivo de la ley tributaria local de un Estado contratante, esté sujeta a tributación allí debido a su domicilio, residencia, lugar de constitución u organización, sede de la alta gerencia u oficina principal, sede de administración o cualquier otro criterio de naturaleza similar ${ }^{17}$.

Apréciese de lo anterior cómo se recurre a la definición textual del MOCDE, el cual, a diferencia del Modelo de Convenio de las Na- ciones Unidas (MONU), no indica el concepto de "nacionalidad" como criterio análogo. Al respecto, esa omisión puede llevar a plantear el interrogante de si una persona natural, que es nacional colombiana, y que por dicho motivo es residente fiscal en el país, por ser, por ejemplo, su cónyuge residente fiscal en Colombia ${ }^{18}$, puede acceder al tratado dado que su residencia fiscal en Colombia está atada, por decirlo de alguna manera, a su nacionalidad o pasaporte colombiano.

A pesar de que existe una postura en virtud de la cual se concluiría que la persona antes señalada no sería residente para efectos del CDI por tener una residencia dada por su nacionalidad (partiendo del supuesto que la nacionalidad no está expresamente señalada por el MOCDE como pauta de residencia), consideramos que la nacionalidad sí puede ser empleada como criterio análogo de resi-

\footnotetext{
${ }^{16}$ El numeral 2) del artículo 3 del CDI señala: "2. Para la aplicación del presente Convenio en cualquier momento por un Estado Contratante, cualquier término no definido en el mismo, a menos que de su contexto se infiera una interpretación diferente o las autoridades competentes acuerden un significado diferente de conformidad con las disposiciones del Artículo 24, tendrá el significado que tiene en ese momento, conforme a la legislación de ese Estado Contratante relativa a los impuestos a los que se aplica el Convenio, prevaleciendo cualquier significado bajo la legislación tributaria aplicable de ese Estado Contratante sobre el significado dado al término bajo otras leyes de ese Estado Contratante".

${ }^{17}$ El numeral 1) del artículo 4 del CDI señala: "A los efectos del presente Convenio, el término 'residente de un Estado Contratante' significa toda persona que, bajo las leyes de ese Estado Contratante, esté sujeta a tributación en ese Estado en razón de su domicilio, residencia, lugar de constitución u organización, sede de la alta gerencia u oficina principal, sede de administración o cualquier otro criterio de naturaleza similar, y también incluye a ese Estado Contratante y cualquier subdivisión política o autoridad local del mismo, así como un fondo de pensiones reconocido de ese Estado Contratante. Sin embargo, este término no incluye a ninguna persona que esté sujeta a tributación en ese Estado Contratante con respecto a las rentas procedentes únicamente de fuentes de ese Estado Contratante".

${ }^{18}$ Sobre este tópico, téngase en cuenta que el artículo 10 del Estatuto Tributario señala: "Se consideran residentes en Colombia para efectos tributarios las personas naturales que cumplan con cualquiera de las siguientes condiciones: (...) 3. Ser nacionales y que durante el respectivo año o periodo gravable: a.) Su cónyuge o compañero permanente no separado legalmente o los hijos dependientes menores de edad, tengan residencia fiscal en el país; o, b). El cincuenta por ciento $(50 \%)$ o más de sus ingresos sean de fuente nacional; o, c). El cincuenta por ciento $(50 \%)$ o más de sus bienes sean administrados en el país; o, d). El cincuenta por ciento $(50 \%)$ o más de sus activos se entiendan poseídos en el país; e). Habiendo sido requeridos por la Administración Tributaria para ello, no acrediten su condición de residentes en el exterior para efectos tributarios; o, f.) Tengan residencia fiscal en una jurisdicción calificada por el Gobierno Nacional como paraíso fiscal”.
} 
dencia, dado que, de no ser así, solamente podrían acceder a la red de CDI de Colombia, aquellos colombianos que cumplan con el criterio de estadía física en el país de los 183 días $^{19}$.

Como resulta lógico, el CDI indica que también se consideran como residentes fiscales a efectos del convenio, a los Estados Contratantes, es decir, tanto a Colombia como a Japón, y a cualquier subdivisión política o autoridad local de estos últimos, al igual que los fondos de pensiones reconocidos en cada país. De la misma suerte de lo que ocurre en el MOCDE, el CDI no considera como "residente fiscal" a aquellas personas que solo están sometidas a tributación de manera exclusiva por las rentas de fuente de alguno de estos países.

Aquí debemos indicar que posteriormente el CDI establece los parámetros generales de las reglas de desempate (tie-breaker rules), para resolver el inconveniente tributario que surge en el evento en el cual una persona na- tural resulta siendo residente fiscal en ambos países, y así evitar una sobre imposición por conflictos de residencia-residencia.

Añádase a esto, sin entrar en un análisis detallado del tema, que como primer criterio se emplea el de vivienda permanente para resolver el conflicto; ahora, en caso de que la persona tuviese vivienda permanente en ambos países, la regla se resuelve a favor del lugar donde esté su centro de intereses vitales; si no fuere posible determinar dicho centro o no tuviese vivienda permanente en ninguno de los países, será residente en el Estado donde viva, si viviese en ambos o en ninguno, de donde sea nacional. Por último, si no es nacional de ningún país o lo es de ambos, su acceso al CDI queda supeditado a un acuerdo entre las autoridades competentes ${ }^{20}$.

De otro lado, respecto de la residencia para personas jurídicas, es preciso indicar que los criterios indicados en el artículo 4 del CDI son completamente afines a los 
contenidos en el artículo 12-1 del Estatuto Tributario (ET); en consecuencia, una sociedad que sea considerada como "nacional" a efectos tributarios colombianos, por tener, por ejemplo, su sede de dirección efectiva o domicilio principal en el país podrá acceder primia facie al CDI.

Por añadidura al tema, en lo que concierne a las reglas de desempate para sociedades o entidades con residencia dual, el CDI Colombia-Japón acogió la última normativa de vanguardia al respecto moldeada bajo el esquema BEPS.

Recuérdese que antes de la actualización del MOCDE en 2017, los conflictos de residencia dual de personas diferentes a las naturales se resolvía a favor del país de ubicación de la sede efectiva de administración. Sin embargo, los parágrafos 45 a 48 de la acción 6 de BEPS trajeron a colación el riesgo potencial que representaban de antemano estas entidades para generar elusión o evasión fiscal (Cabrera, Cabrera, 2019).

Bajo esta perspectiva, el artículo 4 del MOCDE fue actualizado para incluir una regla en virtud de la cual las entidades con residencia dual no tienen derecho de acceder al tratado fiscal a menos que exista un acuerdo previo entre las autoridades tributarias competentes. Sobre el particular, el numeral 3) del artículo 4 del CDI señala:

3. Cuando, en virtud de las disposiciones del párrafo 1 , una persona distinta de una persona natural sea residente de ambos Estados
Contratantes, las autoridades competentes de los Estados Contratantes procurarán determinar de común acuerdo el Estado Contratante del que se considerará que esa persona es residente para los efectos del presente Convenio, teniendo en cuenta la sede de su alta gerencia u oficina principal, su sede de administración efectiva, el lugar donde está incorporada o de otra manera constituida, y cualquier otro factor relevante. En ausencia de tal acuerdo, dicha persona no tendrá derecho a ningún beneficio o exención del impuesto proporcionado por el Convenio.

Lo anterior está en línea con la postura de Colombia en su adhesión a la OCDE, dado que el país hizo la siguiente reserva:

Colombia se reserva el derecho de incluir el lugar de constitución o un criterio similar en el parágrafo 1. Colombia también se reserva el derecho de negar beneficios según la Convención, a personas con doble residencia, excepto personas naturales" (destacado fuera del original).

Por último, no debe perderse de vista que el protocolo del acuerdo, que hace parte integral del mismo, señala que el término "residente de un Estado Contratante" incluye un fondo de cesantías de Colombia.

\section{Establecimiento permanente}

En primera medida, la primera parte del artículo 5 del CDI trae la misma definición de establecimiento permanente (EP) "regla base" contenida en el MOCDE ${ }^{21}$. De la mis-

${ }^{21}$ Dicha norma señala: "1. Para los efectos del presente Convenio, el término "establecimiento permanente' significa un lugar fijo de negocios a través del cual una empresa realiza toda o parte de su actividad". 
ma manera, el numeral 2) de dicho artículo del CDI contempla los mismos ejemplos de "lugares fijos de negocios" que de antaño ha establecido el numeral 2) del artículo 5 del $\mathrm{MOCDE}^{22}$.

Es necesario resaltar aquí que el numeral 3) del artículo 5 del CDI, al igual que varios de los tratados fiscales ya firmados por Colombia, contempla la figura de un EP de servicios (el cual no está en la plantilla genérica del MOCDE, aunque los comentarios a dicho tratado lo desarrollan), en donde se indica que un EP también comprende:

(a) una obra, un proyecto de construcción, ensamblaje o instalación o actividades de supervisión en relación con los mismos, pero solo si dicha obra, proyecto o actividades duran más de 183 días.

(b) la prestación de servicios, incluidos servicios de consultoría, por parte de una empresa a través de empleados u otro personal contratado por la empresa para tal fin, pero solo si las actividades de esa naturaleza continúan (para el mismo proyecto o un proyecto relacionado) dentro de un Estado Contratante por un período o períodos agregados que suman más de 183 días en cualquier período de doce meses que comience o termine en el año fiscal correspondiente.

Para efectos de la anterior regla, se prevé una norma antiabuso que fue inicialmente descrita en la acción 7 del plan BEPS, en virtud de la cual los tiempos empleados por labores de "empresas estrechamente vinculada" deben agregarse para efectos de evitar una desmembración temporal de los contratos en entidades vinculadas (splitting up of contracts), que genere el no cumplimiento del umbral temporal de los 183 días y, así, evitar la activación de un EP.

En adición, para la aplicación de esta regla antiabuso, el numeral 9) del artículo 5 CDI, inspirado en el BEPS y el MOCDE 2017, contempla la definición del concepto de "empresa o persona estrechamente vinculada" en los siguientes términos:

9. A los efectos de este Artículo, una persona o empresa está estrechamente vinculada con una empresa si, en vista de todos los hechos y circunstancias pertinentes, una tiene el control sobre la otra o ambas están bajo el control de las mismas personas o empresas. En todo caso, se considerará que una persona o empresa está estrechamente vinculada con una empresa si participa, directa o indirectamente, en más del 50 por ciento del interés en los beneficios de la otra (o, en el caso de una sociedad, posee más del 50 por ciento del conjunto de los derechos de voto, y del valor de las acciones de la sociedad o de la participación en su patrimonio) o si otra persona o empresa participa, directa o indirectamente, en más del 50 por ciento del interés en los beneficios (o, en el caso de una sociedad, posee más del 50 por ciento del conjunto de los derechos de voto, y del

\footnotetext{
${ }^{22}$ Dicha norma señala: "2. El término 'establecimiento permanente' incluye especialmente: (a) la sede de administración; (b) una sucursal; (c) una oficina; (d) una fábrica; (e) un taller; y (f) una mina, un pozo de petróleo o gas, una cantera o cualquier otro lugar de exploración, explotación o extracción de recursos naturales".
} 
valor de las acciones de la sociedad o de la participación en su patrimonio) de la persona y la empresa o de las dos empresas.

Posteriormente, el CDI señala que las denominadas "actividades preparatorias y auxiliares", no generan primia facie un EP, aunque ya se estable la regla BEPS en virtud de la cual se exige que la actividad global del lugar fijo de negocios sea de carácter preparatorio o auxiliar ${ }^{23}$.

Igualmente, inspirado en el MOCDE de 2017, se trae una exclusión para las actividades preparatorias y auxiliares respecto de "lugares fijos de negocios" mantenidos por empresas vinculadas en los siguientes términos:

El párrafo 4 no se aplicará a un lugar fijo de negocios que sea utilizado o mantenido por una empresa si dicha empresa o una empresa estrechamente vinculada lleva a cabo actividades de negocios en el mismo lugar o en otro lugar en el mismo Estado Contratante y:

(a) ese lugar u otro lugar constituye un establecimiento permanente para la empresa o para la empresa estrechamente vinculada en virtud de las disposiciones de este Artículo; o

(b) el conjunto de la actividad resultante de la combinación de las actividades realizadas por las dos empresas en el mismo lugar, o por la misma empresa o empresas estrechamente vinculadas en los dos lugares, no es de carácter preparatorio o auxiliar, siempre que los negocios desarrollados por las dos empresas en el mismo lugar, o por la misma empresa o empresas estrechamente vinculadas en los dos lugares, constituyan funciones complementarias que forman parte de una operación comercial cohesionada.

De otro lado, frente al denominado EP de agencia o personal, el CDI incluyó los más recientes avances del plan de BEPS, particularmente para atacar las denominadas estructuras de comisionistas o similares, al indicar que también será considerado como "agente dependiente" aquel que concluya habitualmente contratos o desempeñe habitualmente el rol principal que conduce a la celebración de contratos que se concluyen de manera rutinaria sin modificación material por parte de, y estos contratos son:

(a) a nombre de la empresa; o

\footnotetext{
${ }^{23}$ El numeral 4 del Artículo 5 del CDI señala que: "Sin perjuicio de las disposiciones precedentes a este Artículo, se considerará que el término "establecimiento permanente" no incluye: (a) el uso de instalaciones con el único fin de almacenar, exhibir o entregar bienes o mercancías pertenecientes a la empresa; (b) el mantenimiento de un depósito de bienes o mercancías pertenecientes a la empresa con el único fin de almacenarlos, exhibirlos o entregarlos; (c) el mantenimiento de un depósito de bienes o mercancías pertenecientes a la empresa con el único fin de ser procesadas por otra empresa; (d) el mantenimiento de un lugar fijo de negocios con el único fin de comprar bienes o mercancías, o de recopilar información, para la empresa; (e) el mantenimiento de un lugar fijo de negocios con el único fin de llevar a cabo, para la empresa, cualquier otra actividad; o (f) el mantenimiento de un lugar fijo de negocios con el único fin de realizar cualquier combinación de actividades mencionadas en los subpárrafos (a) hasta el (e), siempre que dicha actividad o, en el caso del subpárrafo (f), la actividad global del lugar fijo de negocios, sea de carácter preparatorio o auxiliar".
} 
(b) para la transferencia de la propiedad, o para la concesión del derecho de uso, de una propiedad de esa empresa o que la empresa tiene derecho a usar; o

(c) para la prestación de servicios por parte de esa empresa.

Adicionalmente, el numeral 6) del artículo 5 del CDI, el cual consagra la excepción de agentes independientes, señala que no se considerará de naturaleza independiente aquel agente que actué exclusiva o casi exclusivamente a favor de una empresa, norma originaria del MONU y copiado por el plan de BEPS $^{24}$.

\section{Rentas inmobiliarias}

Mediante el artículo 6 del CDI se regula la tributación de las denominadas rentas inmobiliarias (incluidas las rentas agrícolas y forestales), en donde se mantiene la máxima del MOCDE de no limitar en ninguna circunstancia su gravamen en el Estado de la fuente ${ }^{25}$.

A continuación, el CDI copia la regla del MOCDE en la cual se prevé una definición especial del término "bienes inmuebles", la cual consiste en una remisión a la norma- tiva interna del Estado donde está ubicado el bien; por lo tanto, para fines ilustrativos, habría que remitirse a las normas del Código Civil, que traen la definición de los bienes inmuebles, en caso que se esté aplicando este artículo 6 del CDI desde la perspectiva colombiana.

En adición, el CDI indica que el término incluirá, en todos los casos, los bienes accesorios a los bienes inmuebles, el ganado y los equipos utilizados en las explotaciones agrícolas y forestales, los derechos a los cuales son aplicables las disposiciones de Derecho privado relativas a los bienes raíces, el usufructo de bienes inmuebles y los derechos a percibir pagos variables o fijos como contraprestación por la explotación o el derecho de explotación de yacimientos minerales, fuentes y otros recursos naturales, mientras que las naves y aeronaves no se considerarán bienes inmuebles (todo lo anterior copiado fielmente del MOCDE).

También se establece que la regla distributiva será aplicable a las rentas derivadas del uso directo, arrendamiento o aparcería, al igual que de cualquier otra forma de explotación de los bienes inmuebles ${ }^{26}$, y se aplican

\footnotetext{
${ }^{24}$ El numeral 7) del artículo 5 del CDI señala que: "El párrafo 6 no aplicará cuando la persona que actúe en un Estado Contratante en nombre de una empresa del otro Estado Contratante realice negocios en el Estado Contratante mencionado en primer lugar como agente independiente y actúe a favor de la empresa en el curso normal de esa actividad. Sin embargo, cuando una persona actúe exclusivamente o casi exclusivamente en nombre de una o más empresas con las que esté estrechamente vinculada, esa persona no se considerará un agente independiente en el sentido del presente párrafo con respecto a dichas empresas".

${ }^{25}$ El numeral 1) del artículo 6 del CDI señala: "1. Las rentas que un residente de un Estado Contratante obtenga de bienes inmuebles (incluidas las rentas procedentes de actividades agrícolas o forestales) situadas en el otro Estado Contratante, pueden someterse a imposición en ese otro Estado Contratante".

${ }^{26}$ El numeral 3) del artículo 6 del CDI señala: "Las disposiciones del párrafo 1 son aplicables a las rentas derivadas del uso directo, arrendamiento o aparcería, así como de cualquier otra forma de explotación de los bienes inmuebles".
} 
igualmente a las rentas derivadas de bienes inmuebles de una empresa ${ }^{27}$.

Al igual de lo que ocurre en otros artículos, la redacción del artículo 6 del CDI tiene proximidad con la reserva puntual que hizo Colombia al MOCDE, dado que se estableció lo siguiente:

Colombia se reserva el derecho de incluir derechos relacionados con todos los recursos naturales según este Artículo. Colombia también se reserva el derecho de cambiar la definición de "bienes inmuebles" para que expresamente incluya otros bienes.

\section{Empresas relacionadas}

De la manera en que es conocido, el artículo 9 del MOCDE establece una definición de "empresas relacionadas" para fines principalmente de la aplicación del régimen de precios de transferencia. Así las cosas, el artículo 9 del CDI establece la misma definición del MOCDE respecto de lo que se debe entender por empresas vinculadas a efectos del convenio ${ }^{28}$.
Desde luego, la segunda parte del artículo 9 del CDI, siguiendo a cabalidad el MOCDE, establece la única regla que permite corregir casos de la llamada "doble imposición económica", al obligar que cuando un país realice un ajuste de precios de transferencia, el otro Estado deba permitir la corrección correlativa siempre que se demuestre el cumplimiento del principio de plena competencia en la transacción ${ }^{29}$.

\section{Dividendos}

En materia de dividendos, el artículo 10 del CDI no restringe del todo el Derecho tributario al país de la fuente, es decir, el Estado donde está ubicada la sociedad que gira el dividendo, pero sí lo limita a una alícuota determinada, siempre que el beneficiario efectivo sea un residente del otro Estado contratante.

En línea con lo anterior, la alícuota máxima de retención en la fuente por concepto de dividendos que puede ser aplicada en el país de la fuente, es la que se presenta en la siguiente tabla:

\footnotetext{
${ }^{27}$ El numeral 4) del artículo 6 del CDI señala: "Las disposiciones de los párrafos 1 y 3 se aplican igualmente a las rentas derivadas de bienes inmuebles de una empresa".

${ }^{28}$ Dicha norma señala: "1. Cuando (a) una empresa de un Estado Contratante participe directa o indirectamente en la dirección, el control del capital de una empresa del otro Estado Contratante, o (b) las mismas personas participen directa o indirectamente en la dirección, el controlo el capital de una empresa de un Estado Contratante y de una empresa del otro Estado Contratante, y, en uno y en otro caso, las dos empresas estén, en sus relaciones comerciales o financieras, unidas por condiciones acordadas o impuestas que difieran de aquellas que serían convenidas entre empresas independientes, las utilidades que se habrían obtenido por una de las empresas de no existir dichas condiciones, y que de hecho no se han realizado a causa de las mismas, podrán ser incluidas en las utilidades de esa empresa y ser sometidas a imposición en consecuencia".

${ }^{29}$ La segunda parte del artículo señala: "2. Cuando un Estado Contratante incluya en las utilidades de una empresa de ese Estado Contratante -y en consecuencia someta a imposición- utilidades sobre las cuales una empresa del otro Estado Contratante ha sido sometida a imposición en ese otro Estado Contratante, y las utilidades así incluidas correspondan a las que habrían sido obtenidas por la empresa del Estado Contratante mencionado en primer lugar si las condiciones convenidas entre las dos empresas hubieran sido las que se habrían acordado entre empresas independientes, ese otro Estado Contratante deberá hacer el correspondiente ajuste del monto del impuesto que haya percibido sobre dichas utilidades. Para determinar dicho ajuste, se tendrán en cuenta las demás disposiciones de este Convenio, y las autoridades competentes de los Estados Contratantes se consultarán entre ellas de ser necesario".
} 


\begin{tabular}{|c|c|}
\hline $\begin{array}{l}\text { Alícuota o ta- } \\
\text { rifa máxima } \\
\text { de retención } \\
\text { en la fuente }\end{array}$ & Condición \\
\hline $0 \%$ & $\begin{array}{l}\text { Que el beneficiario efectivo sea un } \\
\text { "fondo de pensión reconocido" y que } \\
\text { el dividendo de derive de su actividad } \\
\text { económica (administrar o proporcionar } \\
\text { beneficios de jubilación y beneficios } \\
\text { auxiliares o incidentales u otra remu- } \\
\text { neración similar a personas). }\end{array}$ \\
\hline $5 \%$ & $\begin{array}{l}\text { Que el beneficiario efectivo sea una } \\
\text { sociedad que ha poseído directa o indi- } \\
\text { rectamente al menos el } 20 \% \text { del poder } \\
\text { de voto de la sociedad que paga los } \\
\text { dividendos durante un período de seis } \\
\text { meses que incluye la fecha en la que } \\
\text { se determina el derecho sobre los divi- } \\
\text { dendos (para el cálculo de ese período, } \\
\text { no se tendrán en cuenta los cambios de } \\
\text { propiedad que resultarían directamen- } \\
\text { te de una reorganización corporativa, } \\
\text { como una fusión o escisión, de la so- } \\
\text { ciedad que es el beneficiario efectivo } \\
\text { de los dividendos o que paga los di- } \\
\text { videndos). }\end{array}$ \\
\hline $15 \%$ & $\begin{array}{l}\text { (a) dividendos pagados por una socie- } \\
\text { dad residente en Colombia, con cargo } \\
\text { a utilidades que no han estado sujetas a } \\
\text { impuestos sobre la renta a nivel de esa } \\
\text { sociedad en Colombia; o } \\
\text { (b) dividendos pagados por una socie- } \\
\text { dad que es residente de Japón, y que } \\
\text { son deducibles al computar las rentas } \\
\text { gravables de esa sociedad en Japón. }\end{array}$ \\
\hline $10 \%$ & En todos los demás casos. \\
\hline
\end{tabular}

Como puede verse, hay una influencia y también una desviación del MOCDE. Acontece que el MOCDE de 2017, por influencia de BEPS, requiere que el accionista haya poseído las acciones por lo menos 365 días antes de su pago, para poder acceder a las tarifas reducidas de retención en la fuente (Cabrera, Cabrera 2018b).

Sin embargo, el CDI fue incluso menos severo que el MOCDE al exigir solamente dicha posesión por un periodo de 6 meses, es decir, la mitad del requerido por los nuevos estándares BEPS.

Adicionalmente, sobre el tópico de las alícuotas no hubo correspondencia con la reserva de Colombia al MOCDE, dado que en dicho documento el país se reservó el derecho de aplicar una tarifa no menor al $10 \%$, pero, como se observó, el CDI contempla tarifas del $5 \%$ e incluso del $0 \%$.

Empero, es claro que de todas maneras estas tarifas del CDI son más benévolas que las domésticas del artículo 245 del ET, que consagra aquella del llamado "impuesto al dividendo" del 7,5\% y la del denominado "impuesto de igualación" (que corresponde a la tarifa general de renta aplicable en el período gravable más el "impuesto al dividendo" del 7,5\% sobre el dividendo neto).

De otro lado, en lo que se refiere a las remesas de utilidades de un EP o sucursal a su oficina principal, el artículo 7 del CDI trae una ficción en virtud de la cual estas se pueden someter a imposición en Colombia de la siguiente manera:

\begin{tabular}{|c|c|}
\hline $\begin{array}{c}\text { Alícuota o } \\
\text { tarifa máxima } \\
\text { de retención } \\
\text { en la fuente }\end{array}$ & Condición \\
\hline $15 \%$ & $\begin{array}{l}\text { Que las utilidades transferidas no ha- } \\
\text { yan estado sujetas a impuestos sobre } \\
\text { la renta de acuerdo con la ley de Co- } \\
\text { lombia antes de dicha transferencia. }\end{array}$ \\
\hline $5 \%$ & $\begin{array}{l}\text { Para las utilidades transferidas en to- } \\
\text { dos los demás casos. }\end{array}$ \\
\hline
\end{tabular}

A pesar de que esta regla respecto de los EP se encuentra contenida en el artículo 7 (beneficios empresariales) y no en el artículo 10 (dividendos), consideramos que el efecto práctico de la disposición se traduce en que 
se podría aplicar la normativa del artículo 30 del ET, la cual señala la fícción de considerar como "dividendo" a efectos fiscales la remesa de rentas de un EP o sucursal a su oficina principal ${ }^{30}$.

Lo anterior con la finalidad de evitar arbitramentos fiscales en el empleo de sucursales o EP sobre filiales nivelando para estas últimas los dos niveles de tributación, es decir, el nivel corporativo (primer nivel de tributación) y la retención en la fuente sobre el dividendo (segundo nivel de tributación) (Cabrera Cabrera, 2018c), dado que por virtud de la Ley 1111 de 2006 se derogó el impuesto de remesas en el país.

Para esta situación se siguió la reserva de Colombia a la entrada a la OCDE, aunque no tratando estas transferencias como "beneficio empresarial" de la manera en que ocurre en el CDI con Japón, dado que en esa ocasión Colombia dispuso lo que se presenta a continuación:

2. Colombia también se reserva el derecho de aplicar sus regulaciones internas sobre la tributación de dividendos distribuidos de utilidades que no hayan sido objeto de impuesto al nivel de la compañía, e imponer su impuesto sobre la transferencia de utilidades atribuibles a establecimientos permanentes que no hayan sido objeto impuesto en Colombia.

Juntamente con lo anterior, frente a la reserva del artículo 24 del MOCDE, el cual versa sobre el principio de no discriminación, la reserva realizada por Colombia fue la siguiente:

Artículo 24: Colombia se reserva su posición en la segunda oración del parágrafo 1 . Colombia también se reserva el derecho de gravar impuesto sobre la transferencia de utilidades atribuibles a establecimientos permanentes. Colombia se reserva además el derecho restringir el alcance del Artículo a impuestos cubiertos por la Convención.

Ahora bien, el numeral 2) del artículo 10 del CDI copió la definición de dividendo prevista en el MOCDE, la cual, debe decirse, hace al final una remisión general a que también será "dividendo" las rentas derivadas de acciones según las leyes del país de donde pertenece la sociedad que realiza la distribución ${ }^{31}$.

Asimismo, el CDI también contempla la figura del llamado "EP proviso", establecida en las rentas pasivas del MOCDE, en virtud de

\footnotetext{
${ }^{30}$ Dicha norma señala: “Artículo 30. Definición de dividendos o participaciones en utilidades: Se entiende por dividendos o participaciones en utilidades: 1 . Toda distribución de beneficios, en dinero o en especie, con cargo a patrimonio que se realice a los socios, accionistas, comuneros, asociados, suscriptores o similares, excepto la disminución de capital y la prima en colocación de acciones. 2. La transferencia de utilidades que corresponden a rentas y ganancias ocasionales de fuente nacional obtenidas a través de los establecimientos permanentes o sucursales en Colombia de personas naturales no residentes o sociedades y entidades extranjeras, a favor de empresas vinculadas en el exterior".

${ }^{31}$ Dicha definición textual del CDI es: "El término ‘dividendos' tal como se utiliza en este Artículo significa la renta derivada de acciones u otros derechos, no siendo créditos, que permitan participar en las utilidades, así como las rentas derivadas de otros derechos que están sujetos al mismo tratamiento fiscal que las rentas derivadas de acciones según las leyes del Estado Contratante del que la sociedad que realiza la distribución es residente".
} 
la cual las normas especiales del artículo 10 del CDI no serán aplicables cuando el dividendo sea de propiedad económica de un EP (atribuible a dicho EP o vinculado económicamente al él) que el perceptor de dividendo posea en el país de la fuente, en cuyo caso serán aplicables las reglas de tributación generales de los beneficios empresariales de que tratan tanto el artículo 7 del CDI como el del MOCDE ${ }^{32}$.

\section{Intereses}

Comencemos por indicar sobre este concepto que, frente a la tributación de intereses pagados por un residente de un Estado a un residente del otro, el CDI no restringe su tributación en la fuente, pero sí la limita a un alícuota al igual que los dividendos, siempre que el beneficiario efectivo sea un residente del otro Estado contratante.

De ahí se explica por qué el artículo 11 del CDI establece una alícuota fija del 10\%, la cual aplica cuando un residente de un Estado, por ejemplo, una sociedad colombiana, le paga un interés a un residente del otro Estado, por ejemplo, un prestamista japonés. Asimismo, debe indicarse que esta tarifa del $10 \%$ ha sido la alícuota general que ha negociado Colombia en sus múltiples CDI.

Así las cosas, es preciso señalar que esta tarifa es a todas luces más beneficiosa que la tarifa colombiana por pagos al exterior contemplada en el artículo 408 del ET, la cual podría ser del $15 \%$ o del $20 \%$, dependiendo de si la maduración del crédito o es o no superior a un año.

Sin embargo, el CDI contempla algunos casos en los cuales el interés no podrá ser sometido a retención en la fuente por impuesto de renta en el Estado de localización del deudor que lo paga, cuando:

A. El interés es de propiedad efectiva un Estado Contratante, una subdivisión política o autoridad local del mismo o su banco central o cualquier otra institución de propiedad exclusiva de un Estado Contratante o una subdivisión política o autoridad local del mismo.

B. El interés es de propiedad efectiva de un residente con respecto a créditos garantizados, asegurados o indirectamente financiados por un Estado Contratante, una subdivisión política o autoridad local del mismo, el banco central o cualquier institución de propiedad exclusiva de un Estado Contratante o una subdivisión política o autoridad local del mismo.

C. El interés es de propiedad efectiva de un residente que sea:

i. Una institución financiera; o

ii. Un banco, siempre que se trate de créditos otorgados por un período de al menos tres años.

D. El interés es de propiedad efectiva de un fondo de pensiones reconocido en y que se derive su actividad económica.

\footnotetext{
${ }^{32}$ Tal norma del CDI señala: "Las disposiciones de los párrafos 1, 2, 3 y 4 no se aplicarán si el beneficiario efectivo de los dividendos, siendo un residente de un Estado Contratante, realiza en el otro Estado Contratante, del que es residente la sociedad que paga los dividendos, una actividad empresarial a través de un establecimiento permanente situado allí, y la participación en virtud de la cual se pagan los dividendos esté vinculada efectivamente con dicho establecimiento permanente. En tal caso, se aplicarán las disposiciones del Artículo 7”.
} 
E.El interés es de propiedad efectiva de un residente de un Estado contratante y pagado con respecto a reclamos de una deuda que surja como parte de la venta a crédito de equipo o mercancía por parte de un residente del otro Estado contratante.

Para efectos de la aplicación de esta regla distributiva de "intereses", el protocolo del CDI señala que el término "institución financiera" significa:

\section{A. Un banco;}

B.Una compañía de seguros; o,

C.Una empresa que deriva sustancialmente sus ingresos brutos del desarrollo activo y regular de un negocio crediticio o financiero que involucra transacciones con personas no vinculadas, donde la empresa no está vinculada con el pagador de los intereses.

Adicionalmente, se señala que el término "negocio crediticio o financiero" incluye el negocio de emitir cartas de crédito, proporcionar garantías o proporcionar servicios de tarjetas de crédito.

Por su parte, el numeral 3) del artículo 12 del CDI establece una definición de "intereses" similar a aquella contenida en el MOCDE en los siguientes términos:
El término "interés" empleado en este Artículo significa las rentas de créditos de cualquier naturaleza, con o sin garantía hipotecaria, con o sin cláusula de participación en las utilidades del deudor, y en particular, las rentas provenientes de valores públicos y las rentas de bonos u obligaciones, incluidos las primas y los premios relacionados con dichos títulos, así como cualquier otra renta que esté sometida al mismo tratamiento tributario que las rentas provenientes de préstamos dinerarios bajo la legislación del Estado Contratante del cual provengan. No obstante, las rentas reguladas en el Artículo 10 y los recargos por demora en el pago no se considerarán intereses a los efectos del presente Artículo.

Ahora bien, se contempla la misma regla de origen o fuente de los intereses del numeral 5) del artículo 11 del MOCDE, al indicar que los intereses se consideran provenientes de un Estado contratante cuando el deudor tiene residencia allí, o cuando el deudor, siendo o no residente de un Estado contratante, posee en dicho lugar un EP frente al cual se ha contraído la deuda y el pago del interés es asumido por dicho $\mathrm{EP}^{33}$.

Por último, siguiendo la estructura del MOCDE, el numeral 6) del CDI consagra la pauta en virtud de la cual las reglas especiales del artículo 11 no serán aplicables a

\footnotetext{
${ }^{33}$ Dicha norma del CDI dice textualmente: "Los intereses se considerarán procedentes de un Estado Contratante cuando el pagador es un residente de ese Estado Contratante. Sin embargo, cuando la persona que paga los intereses, ya sea o no residente de un Estado Contratante, tiene en un Estado Contratante un establecimiento permanente en relación con el cual se haya contraído el endeudamiento por el cual se pagan los intereses, yesos intereses son asumidos por dicho establecimiento permanente, dichos intereses se considerarán procedentes del Estado Contratante en el que se encuentre el establecimiento permanente".
} 
aquella parte que exceda las condiciones que no sean de mercado fijadas entre el deudor $\mathrm{y}$ el acreedor ${ }^{34}$, norma que funge como un respaldo o back up a la disposición general de precios de transferencia del CDI contenida en su artículo 9.

\section{Regalías}

Siguiendo la postura que ha tenido Colombia en sus CDI, que también quedó reproducida en sus reservas al MOCDE, el tratado con Japón permite la tributación en la fuente de las regalías, pero claro está, con unos topes máximos en las tarifas de retención. Así las cosas, las alícuotas para regalías incluidas en el CDI son:

\begin{tabular}{|c|l|}
\hline $\begin{array}{c}\text { Alícuota o tarifa } \\
\text { máxima de retención } \\
\text { en la fuente }\end{array}$ & \multicolumn{1}{c|}{ Concepto } \\
\hline $2 \%$ & $\begin{array}{l}\text { Por el uso o el derecho de uso } \\
\text { de equipos industriales, co- } \\
\text { merciales o científicos. }\end{array}$ \\
\hline $10 \%$ & En todos los demás casos. \\
\hline
\end{tabular}

De la manera como se desprende la tabla, estas alícuotas de retención son más favorables que la tarifa general del $20 \%$ por concepto de regalías del artículo 408 del ET.

Respecto de lo anterior, es importante hacer hincapié en que en el MOCDE los arrendamientos de maquinaria industrial, comercial o científica, desde hace varios años dejaron de considerarse como "regalías" para pasar a ser típicos beneficios empresariales, solo gravables en el país de la fuente si le son atribuibles a un EP localizado allí.

Sin embargo, en algunos pocos CDI de Colombia como es el caso, por ejemplo, de España o Suiza, se incluyeron estos arrendamientos como regalías. De todas maneras, el CDI con Japón tiene correspondencia con la reserva hecha por el país al artículo 12 del MOCDE en la cual se dispuso:

Adicionalmente, Colombia se reserva el derecho de incluir en la definición de regalías, pagos para el uso o derecho de uso de equipo industrial, comercial o científico.

Por remate de este punto, consideramos vital resaltar que en esta ocasión no se siguió con una práctica reiterada de Colombia en la negociación de sus acuerdos fiscales, la cual era incorporar la ficción de considerar los servicios técnicos, de asistencia técnica y consultoría, como pagos por regalías gravables en el país donde estaba el pagador. Por lo tanto, no existe en el CDI con Japón, cláusulas de nación más favorecida. Al respecto, téngase en cuenta que la reserva hecha por Colombia al MOCDE sobre este tópico es la siguiente:

Colombia se reserva el derecho de gravar regalías en la fuente. Colombia también se reserva el derecho de incluir pagos recibidos para la provisión de asistencia técnica,

\footnotetext{
${ }^{34}$ El numeral 6) del artículo 11 del CDI señala: “Cuando, por razón de una relación especial entre el pagador y el beneficiario efectivo o entre ambos y con otra persona, el monto del interés excede, por cualquier razón, el monto que habría sido acordado por el pagador y el beneficiario efectivo en ausencia de tal relación, las disposiciones de este Artículo se aplicarán únicamente a la última cantidad mencionada. En tal caso, la parte excedente de los pagos seguirá siendo gravable de acuerdo con las leyes de cada Estado Contratante, teniendo en cuenta las demás disposiciones de este Convenio".
} 
servicios técnicos y servicios de consultoría dentro de la definición de regalías.

Ahora bien, el numeral 4) del artículo 12 del CDI trae la definición de "regalías" para efectos del convenio en los siguientes términos:

(...) los pagos de cualquier tipo recibidos como contraprestación por el uso, o el derecho de uso, de cualquier derecho de autor sobre obras literarias, artísticas o científicas, incluidas las películas cinematográficas, cualquier patente, marca, diseño o modelo, plan, o fórmula o proceso secreto, o cualquier equipo industrial, comercial o científico, o por información relacionada con la experiencia industrial, comercial o científica.

Al igual que lo que ocurre con los intereses, el numeral 4) del artículo 12 contempla la figura del EP proviso frente a regalías vinculadas económicamente a un $\mathrm{EP}^{35}$. Igual- mente, el numeral 5) del artículo referido al permitir el gravamen en fuente de las regalías, trae la misma regla de fuente $\mathrm{u}$ origen descrita previamente en los intereses ${ }^{36}$. Por último, el numeral 6) también se establece la regla de back up de precios de transferencia antes reseñada ${ }^{37}$.

\section{Ganancias de capital}

Así como sucede en el MOCDE, la regla distributiva de imposición sobre las ganancias de capital se encuentra regulada en el artículo 13 del CDI entre Colombia y Japón.

Dicho esto, el tratado con Japón mantiene la regla del numeral 1) del MOCDE en virtud de la cual no se restringe el derecho al Estado de fuente para gravar, conforme a su normativa fiscal doméstica, las ganancias de capital derivadas de la venta de propiedad inmueble allí ubicada ${ }^{38}$.

\footnotetext{
${ }^{35}$ Dicho apartado señala: "Las disposiciones de los párrafos 1 y 2 no se aplicarán si el beneficiario efectivo de las regalías, siendo residente de un Estado Contratante, realiza en el otro Estado Contratante del cual proceden las regalías una actividad empresarial a través de un establecimiento permanente situado allí, y el derecho o propiedad respecto de los cuales se pagan las regalías está efectivamente relacionado con dicho establecimiento permanente. En tal caso, se aplicarán las disposiciones del Artículo 7".

${ }^{36}$ Dicho apartado señala: "Las regalías se considerarán procedentes de un Estado Contratante cuando el pagador sea un residente de ese Estado Contratante. Sin embargo, cuando la persona que paga las regalías, ya sea o no residente de un Estado Contratante, tiene en un Estado Contratante un establecimiento pell11 anente en relación con el cual se ha contraído la obligación de pagar las regalías, y esas regalías son asumidas por ese establecimiento permanente, dichas regalías se considerarán procedentes del Estado Contratante en el que esté situado el establecimiento permanente". ${ }^{37}$ Dicho apartado señala: "Cuando, en razón de una relación especial entre el pagador y el beneficiario efectivo o entre ambos y con otra persona, el monto de las regalías excede, por cualquier razón, el monto que habría sido acordado por el pagador y el beneficiario efectivo en ausencia de tal relación, las disposiciones de este Artículo se aplicarán únicamente a la última cantidad mencionada. En tal caso, la parte excedente de los pagos seguirá siendo imponible de acuerdo con las leyes de cada Estado Contratante, teniendo en cuenta las demás disposiciones de este Convenio". ${ }^{38}$ Sobre el tema, el numeral 1) de Artículo 13 del CDI señala: "Las ganancias que un residente de un Estado Contratante obtenga de la enajenación de bienes inmuebles a los que se refiere el Artículo 6 y situados en el otro Estado Contratante pueden someterse a imposición en ese otro Estado Contratante".
} 
De la misma manera, también se mantiene la pauta del MOCDE según la cual los ingresos originados en la venta de un EP o del mobiliario atribuible a este podrán gravarse de manera ilimitada en el país de la fuente ${ }^{39}$.

Asimismo, para mantener la lógica tributaria que rige a las empresas de transporte internacional, el numeral 3) del CDI, al igual que el MOCDE, dispone que la enajenación de estas naves o aeronaves solo estará gravada en el país de residencia ${ }^{40}$.

Ahora bien, respecto de las rentas originadas en la enajenación de acciones y/o intereses similares, se establece el nuevo estándar BEPS respecto de las entidades conocidas como land rich, es decir, cuando las acciones, o derechos similares como participación en fideicomisos, representan directa o indirectamente más de un $50 \%$ de su valor en propiedad inmueble. En caso anterior, la enajenación podrá gravarse en el país donde se encuentren poseídas las acciones, si en un período de 365 días anteriores a la venta, se cumplió con la regla del $50 \%$ antes referida ${ }^{41}$.

Adicionalmente, existe otra regla en virtud de la cual la venta de acciones también podrá someterse a tributación en el país de la fuente, si el enajenante ha poseído directa o indirectamente, acciones, intereses comparables u otros derechos que representen $10 \%$ o más del capital de la sociedad, pero en cuyo caso el impuesto no podrá exceder del 10\%, en donde esta regla no aplicará si:

(a) la ganancia se deriva de cambios de propiedad como resultado de una reorganización corporativa, como una fusión o escisión (divisive reorganization), de esa sociedad; o

(b) la ganancia es obtenida por un fondo de pensiones reconocido.

Ahora bien, el artículo 13 del CDI termina consagrando la cláusula de catch all en virtud de la cual cualquier otra ganancia de

\footnotetext{
${ }^{39}$ Respecto de esto, el numeral 2) de artículo 13 del CDI señala: "Las ganancias derivadas de la enajenación de bienes, distintos de los bienes inmuebles mencionados en el Artículo 6, que formen parte de la propiedad de un establecimiento permanente que una empresa de un Estado Contratante tenga en el otro Estado Contratante, incluidas las ganancias derivadas de la enajenación de dicho establecimiento permanente (solo o con toda la empresa), puede someterse a imposición en ese otro Estado Contratante".

${ }^{40}$ Dicha norma señala: "Las ganancias que una empresa de un Estado Contratante que opera naves o aeronaves en tráfico internacional obtenga de la enajenación de dichas naves o aeronaves, o de cualquier bien, distinto de los bienes inmuebles a que se refiere el Artículo 6, relativo a la operación de dichas naves o aeronaves, solo estarán sometidas a imposición en ese Estado Contratante". ${ }^{41}$ Esta disposición señala: "Las ganancias que un residente de un Estado Contratante obtenga de la enajenación de acciones de una sociedad o intereses comparables, tales como participaciones en una sociedad de personas ("partnership") o fideicomiso ("trust"), pueden someterse a imposición en el otro Estado Contratante si, en cualquier momento durante los 365 días anteriores a la enajenación, el valor de estas acciones o intereses comparables se deriva al menos en un 50 por ciento directa o indirectamente de bienes inmuebles, tal como se define en el Artículo 6, situados en ese otro Estado Contratante, a menos que tales acciones o intereses comparables se negocien en una bolsa de valores reconocida especificada en el subpárrafo (c) del párrafo 6 del Artículo 28 y el residente y las personas relacionadas con ese residente poseen en conjunto 5 por ciento o menos de la clase de dichas acciones o intereses comparables".
} 
capital solo podrá someterse a imposición en el país de residencia de quien enajena ${ }^{42}$.

Para culminar, debe mencionarse que esta regla de ganancias de capital en la venta de acciones tiene cercanía con la reserva realizada por Colombia en su acceso a la OCDE, en donde se señaló:

Colombia se reserva el derecho de gravar ganancias sobre la enajenación de acciones o derechos en una compañía que sea residente Colombia.

\section{Remuneración de directores}

Copiando de manera fiel el artículo 16 del MOCDE, el CDI permite la tributación en la fuente de los pagos realizados a personas en su calidad de miembro de junta directiva u órgano similar según como se desprende del artículo 15 del $\mathrm{CDI}^{43}$.

Por lo tanto, para fines ilustrativos, el CDI permitiría a Colombia gravar los pagos realizados a un residente fiscal japonés por ser miembro de una junta directiva de una sociedad colombiana.

\section{XV.Artistas y deportistas}

Siguiendo las pautas del artículo 17 del MOCDE, el artículo 16 del CDI las replica de manera casi exacta, al permitir la tributación en la fuente de las rentas obtenidas por artistas y deportistas, incluso cuando el pago no se hace directamente al artista o deportista sino a un tercero (norma antiabuso que nació en el MOCDE para evitar triangulaciones en estos pagos $)^{44}$.

\section{Pensiones}

En lo que atañe al régimen tributario de las pensiones, el artículo 17 del CDI trae una regla distributiva similar a aquella del artículo 18 del MOCDE, pero con una redacción distinta ${ }^{45}$.

Basándonos en lo anterior, el CDI señala que las pensiones y otros pagos similares, de propiedad exclusiva de un residente de uno de los Estados contratantes, solo podrán ser sometidas a imposición allí, derivando en que el país de la fuente de la pensión o pago parecido no pueda ejercer tributación sobre los mismos.

\footnotetext{
${ }^{42}$ Dicha parte del artículo señala: "Las ganancias derivadas de la enajenación de cualesquiera bienes, distintos de los mencionados en los párrafos 1, 2, 3, 4 y 5, solo pueden someterse a imposición en el Estado Contratante del que el enajenante es residente".

${ }^{43} \mathrm{El}$ artículo 15 del CDI establece: "Los honorarios de directores y otros pagos similares derivados por un residente de un Estado Contratante en su calidad de miembro de la junta directiva, o de un órgano similar, de una sociedad que sea residente del otro Estado Contratante pueden someterse a imposición en ese otro Estado Contratante".

${ }^{44} \mathrm{El}$ artículo 16 del CDI establece de manera textual: "No obstante las disposiciones del Artículo 14, las rentas que un residente de un Estado Contratante obtenga del ejercicio de sus actividades personales en el otro Estado Contratante en calidad de artista del espectáculo, como artistas de teatro, cine, radio o televisión, o como músico o como deportista, pueden ser sometidas a imposición en ese otro Estado. No obstante, las disposiciones del Artículo 14, cuando las rentas derivadas de las actividades personales de un artista del espectáculo o de un deportista, en su calidad de tal, se atribuyan no al propio artista del espectáculo o deportista, sino a otra persona, dichas rentas pueden someterse a imposición en el Estado Contratante en el cual se realicen las actividades del artista del espectáculo o del deportista".

${ }^{45} \mathrm{El}$ artículo 17 del CDI señala: "Las pensiones y otras remuneraciones similares que sean de propiedad exclusiva de un residente de un Estado Contratante solo pueden someterse a imposición en ese Estado Contratante".
} 
De ahí que pueda decirse que, a diferencia del MOCDE, el CDI no indicó que se trate de pensiones pagadas por un trabajo pasado, $\mathrm{y}$ que adicionalmente este primero exige que la pensión sea de propiedad exclusiva de dicho residente.

Adicionalmente, el CDI tampoco indica que las reglas de su artículo 17 aplicarán sin perjuicio de las reglas de tributación de los pagos por servicios de gobierno o por el ejercicio de funciones públicas, con lo cual estas normas sobre pensiones también aplicarán para estos funcionarios.

\section{Otras rentas}

Mediante el artículo 21 del CDI, se regula la tributación de las denominadas "otras rentas", es decir, rentas que por su naturaleza particular o extraordinaria no se han podido clasificar en otra regla distributiva, ni siquiera como "beneficio empresarial del artículo 7 del convenio.

$\mathrm{Al}$ respecto, la primera parte de dicha disposición reproduce lo contenido en el artículo 21 del MOCDE, que indica una tributación exclusiva sobre estos elementos en el país de residencia de su perceptor, lo cual, obviamente, es congruente con la filosofía del
MOCDE. Así las cosas, el artículo 21 del CDI señala textualmente:

3. No obstante lo dispuesto en los párrafos 1 y 2, las partidas de rentas de un residente de un Estado Contratante no mencionadas en los artículos anteriores del presente Convenio que surjan en el otro Estado Contratante también pueden someterse a imposición en ese otro Estado Contratante.

Avanzando en el análisis de esta norma, su numeral 2) continúa con la regla estándar del MOCDE al indicar que la tributación exclusiva en residencia de las "otras rentas" no es aplicable respecto de ingresos que surjan con ocasión a rentas inmobiliarias según el artículo 6 o imputables a un EP, en cuyo caso estos últimos podrán someterse a imposición en el país de la fuente ${ }^{46}$.

Apartándose de los lineamientos del MOCDE, el numeral 3) del artículo 21 indica que, de todas maneras, las "otras rentas" que obtenga un residente de un Estado en el otro Estado, podrán ser sometidas a imposición en ese último Estado $^{47}$.

En palabras más claras, esta norma permite a Colombia gravar las "otras rentas" que obtiene un residente japonés en Colombia,

${ }^{46}$ El numeral 2) del artículo 21 del CDI señala: "Las disposiciones del párrafo 1 no son aplicables a las rentas, distintas de las derivadas de bienes inmuebles, tal como están definidos en el párrafo 2 del Artículo 6, cuando el beneficiario de dichas rentas, siendo residente de un Estado Contratante, realiza actividades empresariales en el otro Estado Contratante a través de un establecimiento permanente ubicado en ese otro Estado, y el derecho o bien con respecto al cual se pagan las rentas está vinculado efectivamente con dicho establecimiento permanente. En tal caso, se aplicarán las disposiciones del Artículo 7".

${ }^{47}$ El numeral 2) del artículo 21 del CDI señala: "Las partidas de rentas que sean de propiedad efectiva de un residente de un Estado Contratante, cualquiera que sea su procedencia, no mencionadas en los artículos anteriores del presente Convenio, solo pueden someterse a imposición en ese Estado Contratante". 
en donde por motivos del numeral 1) del mismo artículo Japón también podría someterlas a imposición, lo cual podría derivar en una doble imposición que deberá ser corregida empleando el método para aliviar la doble imposición del CDI que será analizado en el acápite siguiente.

Como se desprende de lo anterior, esta parte tiene más proximidad con la regla contenida en el MONU, la cual no limita el derecho al Estado de la fuente de ejercer derecho tributario sobre las "otras rentas" generadas en su territorio.

Bajo esta perspectiva, es preciso mencionar que en esta parte el CDI con Japón refleja la posición impuesta por Colombia en sus reservas de entrada a la OCDE, dado que el país señaló que respecto al artículo 21 del MOCDE:

Artículo 21: Colombia se reserva su posición en este Artículo puesto que desea mantener el derecho de gravar impuestos que resulten de fuentes en Colombia.

\section{Eliminación de la doble imposición}

Dado que existen elementos de rentas que pueden someterse a imposición en ambos Estados, como lo son, por ejemplo, por regla general los dividendos y los intereses, el artículo 22 del CDI establece el método a través del cual se procura la eliminación de esta doble imposición y, así, cumplir con uno de los objetivos principales del tratado.

Siguiendo la práctica de Colombia al respecto (Cabrera Cabrera, 2018d), se optó por prescindir del método de la exención y, en sentido contrario, se incluyó el método del crédito fiscal como mecanismo del CDI para solventar estas situaciones problemáticas de rentas que pudiesen resultar gravables en ambos países.

En adición, al igual que el artículo 23(b) del MOCDE, se impuso un modelo del crédito fiscal ordinario, es decir, un crédito reducido al impuesto hipotético que hubiese pagado esa misma renta en el país de residencia teniendo en cuenta la sustracción de los costos y gastos relacionados.

Ahora bien, para el caso puntual del tratado con Japón, el funcionamiento de dicho crédito fiscal varía dependiendo del Estado que esté obligado a concederlo, es decir, de cuál sería el país de residencia del contribuyente que fue sometido a tributación en el otro Estado (país de la fuente).

En caso de que sea Colombia, se le deberá conceder al contribuyente colombiano la posibilidad de descontar de su impuesto de renta debido en Colombia, el impuesto soportado en el Japón, sujeto a las limitaciones de la normativa doméstica colombiana (por ejemplo, el límite a los descuentos del artículo 259 del ET).

Desde un punto de vista semántico, el CDI se refiere a un "descuento" indicando de manera seguida en paréntesis el término deduction, en inglés; dicho esto, consideramos que esto no tendrá efectos prácticos dado que el método colombiano consiste en un descuento tributario y no en una deducción, aunque no se entiende el motivo por el cual se agregó esta palabra más allá de querer replicar el MOCDE que para este punto consideramos que no era necesario. 
Como se observa, lo anterior no supone a simple vista una gran diferencia o una mejora respecto al método interno del crédito fiscal previsto en el artículo 254 del ET, y más teniendo en consideración que igual aplican las limitaciones internas. Sin embargo, el CDI si pudiera ayudar a casos en los cuales, por ejemplo, el descuento no sea posible en Colombia por motivo a que la renta obtenida en Japón no califique como renta de fuente extranjera de acuerdo con las reglas domésticas del artículo 24 del ET, en cuyo caso, prevalecerá la obligación impuesta por el CDI a Colombia de conceder alivio tributario.

Por su parte, el CDI también señala que cuando de conformidad con las reglas del tratado algún elemento de renta obtenido por un residente fiscal colombiano quede exento de tributación en Colombia, el país podría tener en cuenta dicha renta para calcular el impuesto a cargo restante de dicho contribuyente.

Sobre lo anterior, debe mencionarse que esta misma regla está prevista en el numeral 2) del artículo 23 (b) del MOCDE y resulta en un reflejo del llamado método de exención con progresividad. Sin embargo, es difícil que en la práctica resulte aplicable toda vez que el CDI con Japón no contempló la exención como método de alivio fiscal.

Ahora bien, desde el punto de vista japonés, el CDI indica que el Japón debe otorgar a sus residentes un descuento equivalente al impuesto colombiano. Sin embargo, el monto del crédito no puede exceder del monto del impuesto japonés que resultaría aplicable a esa misma renta.

\section{Principio de no discriminación}

En materia de no discriminación, el CDI Colombia-Japón es fiel al artículo 24 del MOCDE. Sin embargo, no trae la regla en virtud de la cual los apátridas residentes de algún de los Estados contratantes no serán sometidos allí a ningún impuesto u obligación que no sea exigible o que sea más gravosa que aplica a los nacionales de dicho Estado.

\section{Cláusula antiabuso}

Partiendo de la base de que el CDI está a tono respecto de los avances del plan de BEPS, su artículo 28 establece una cláusula general antiabuso que limita el acceso a las disposiciones del acuerdo, y que es casi una réplica exacta del contenido del nuevo artículo 29 del MOCDE. A continuación, se hará una leve descripción de esta cláusula dada su longitud y complejidad, ya que su estudio a profundidad excede los propósitos del presente texto y requeriría un documento independiente.

En este orden de ideas, como lo sugería la acción 6 de BEPS, los CDI debían poseer un estándar mínimo antiabuso, que bien podía ser una cláusula de limitación de beneficios (conocida como LOB por sus siglas en inglés de limit of benefits), o una cláusula de propósito principal (conocida como PPT por sus siglas en inglés de principal purpose test), o incluso ambas o una mezcla de estas (Cabrera, 2018e).

De esta manera, tomando en consideración las anteriores recomendaciones, el artículo 
29 del MOCDE de 2017 establece una cláusula híbrida que incluye una regla tanto LOB (mecanismo principal) como PPT (mecanismo subsidiario).

Así las cosas, no quedándose atrás respecto del MOCDE, el artículo 28 del CDI contempla una cláusula LOB, dado que restringe el acceso de varios de los beneficios del tratado (principalmente en rentas pasivas) solo para aquellas "personas calificadas" 48 según la definición dada por el CDI, aunque levantando esta limitación en algunos casos puntuales en los cuales no se alcanza el umbral de "persona calificada".

\author{
Asimismo, se trae el estándar BEPS para \\ evitar que se obtengan provechos tributarios
}

${ }^{48}$ La cláusula del artículo 28 del CDI es: "Derecho a Beneficios: Salvo que se disponga lo contrario en este artículo, un residente de un Estado Contratante no tendrá derecho a un beneficio que de lo contrario se otorgaría según las disposiciones del párrafo 5 del Artículo 7 o del Artículo 10, 11,12 o 13, a menos que dicho residente sea una persona calificada, tal como se define en el párrafo 2, en el momento en que de lo contrario se otorgaría el beneficio. 2. Un residente de un Estado Contratante será una persona calificada en el momento en que de lo contrario se otorgaría un beneficio de conformidad con las disposiciones del párrafo 5 del Artículo 7 o del Artículo 10, 11, 12 o 13 si, en ese momento, el residente es: (a) una persona natural; (b) ese Estado Contratante, una subdivisión política o autoridad local del mismo, el banco central de ese Estado Contratante, o una agencia u organismo de ese Estado Contratante o subdivisión política o autoridad local; (c) una sociedad u otra entidad, si la clase principal de sus acciones se cotiza regularmente en una o más bolsas de valores reconocidas; (d) un fondo de pensiones reconocido, si, al comienzo del año fiscal para el cual se realiza el reclamo del beneficio, al menos el 50 por ciento de sus beneficiarios, miembros o participantes son personas naturales que son residentes de cualquiera de los Estados Contratantes; o (e) una persona que no sea una persona natural, si, en ese momento y en al menos la mitad de los días de un período de doce meses que incluye ese momento, las personas que son residentes de ese Estado Contratante y que son personas calificadas según los subpárrafos (a), (b), (c) o (d) poseen, directa o indirectamente, al menos el 50 por ciento de las acciones de la persona. 3. (a) Un residente de un Estado Contratante tendrá derecho a un beneficio que de otro modo se otorgaría de conformidad con las disposiciones del párrafo 5 del Artículo 7 o del Artículo 10, 11, 12 o 13, con respecto a una partida de renta descrita en el párrafo o Artículo respectivo, que se deriva del otro Estado Contratante, independientemente si el residente es una persona calificada, si el residente se dedica a un negocio empresarial activo en el primer Estado Contratante, y las rentas derivadas del otro Estado Contratante emanan de, o son incidentales a, esa actividad empresarial. Para los fines de este párrafo, la expresión "negocio empresarial activo" no incluirá las siguientes actividades, ni ninguna combinación de las mismas: (i) operación como una empresa tenedora (holding Company); (ii) supervisión general o administración para un grupo de empresas; (iii) financiación grupal (incluida la centralización de tesorería [cash pooling); (iv) realización o administración de inversiones, a menos que estas actividades sean realizadas por un banco, una empresa de seguros o un corredor de valores registrado en el curso ordinario de sus negocios como tal; o (v) mantel11mlento o administración de propiedad intangible producirla o desarrollarla. (b) Si un residente de un Estado Contratante obtiene una partida de renta de una actividad empresarial realizada por ese residente en el otro Estado Contratante, u obtiene una partida de renta que surge en el otro Estado Contratante de una persona vinculada, las condiciones descritas en el subpárrafo (a) se considerarán satisfechas con respecto a dicha partida de renta, solo si la actividad comercial desarrollada por el residente en el Estado Contratante mencionado en primer lugar, con el que se relaciona la partida de renta, es sustancial en relación con la misma actividad empresarial o actividad complementaria llevada a cabo por el residente o la persona vinculada en el otro Estado Contratante. Si una actividad empresarial es sustancial para los efectos de este párrafo se determinará en función de todos los hechos y circunstancias. (c) Para los efectos de la aplicación del presente párrafo, las actividades empresariales realizadas por personas vinculadas con respecto a un residente de un Estado Contratante se presumirán realizadas por dicho residente. 4. Sin embargo, un residente de un Estado Contratante que no sea una persona calificada tendrá derecho a un beneficio que de lo contrario se otorgaría de conformidad con las disposiciones del 
ilegítimos en estructuras que supongan la triangulación de un EP en terceras jurisdicciones que son ajenas a Colombia y Japón ${ }^{49}$. Adicionalmente, al final del artículo se establece de manera complementaria una cláusula de PPT al indicar que, de todas maneras, los beneficios del CDI no estarán disponibles cuando sea posible concluir del contexto de los hechos y las circunstancias que la obtención de dicho beneficio del trata-

párrafo 5 del Artículo 7 o del Artículo 10,11, 12 o 13 con respecto a una partida de renta descrita en el párrafo o Artículo respectivo si: (a) en el caso de un fondo de pensiones reconocido, al comienzo del año fiscal para el cual se realiza el reclamo del beneficio, al menos el 7S por ciento de sus beneficiarios, miembros o participantes son individuos que son beneficiarios equivalentes; o (b) en todos los demás casos, en el momento en que se otorgaría el beneficio y en al menos la mitad de los días de un período de doce meses que incluye ese momento, las personas que son beneficiarios equivalentes poseen, directa o indirectamente, al menos el $7 \%$ por ciento de las acciones del residente. S. Si un residente de un Estado Contratante no es una persona calificada ni tiene derecho a un beneficio en virtud de los párrafos 3 o 4, la autoridad competente del Estado Contratante en el que se niega un beneficio de conformidad con los párrafos precedentes de este Artículo podrá, no obstante, conceder un beneficio que de lo contrario se otorgaría de conformidad con las disposiciones del párrafo 5 del Artículo 7 o del Artículo 10, 11, 12 o 13 con respecto a una partida de renta descrita en el párrafo o Artículo respectivo, teniendo en cuenta el objeto y el propósito de este Convenio, pero solo si dicho residente demuestra a satisfacción de dicha autoridad competente que ni su establecimiento, adquisición o mantenimiento, ni la realización de sus operaciones, tuvieron como uno de sus principales propósitos la obtención de dicho beneficio. La autoridad competente del Estado Contratante a la que se haya hecho una solicitud en virtud del presente párrafo por parte de un residente del otro Estado Contratante, deberá consultar con la autoridad competente de ese otro Estado Contratante antes de otorgar o negar la solicitud. 6. Para efectos de este artículo: (a) el término "clase principal de acciones" significa la clase o clases de acciones de una sociedad o entidad que representa la mayoría del conjunto de los derechos de voto y el valor de la sociedad o entidad; (b) con respecto a entidades que no son sociedades, el término "acciones" significa participaciones que son comparables a acciones; (c) el término "bolsa de valores reconocida" significa: (i) cualquier bolsa de valores establecida y regulada como tal bajo las leyes de cualquier Estado Contratante; y (ii) cualquier otra bolsa de valores acordada por las autoridades competentes de los Estados Contratantes; (d) dos personas serán "personas vinculadas" si una posee, directa o indirectamente, al menos el 50 por ciento del interés efectivo en la otra (o, en el caso de una sociedad, al menos el 50 por ciento del conjunto de los derechos de voto y el valor de las acciones de la sociedad) u otra persona posee, directa o indirectamente, al menos el 50 por ciento de la participación efectiva (o, en el caso de una sociedad, al menos el 50 por ciento del conjunto de los derechos de voto y el valor de las acciones de la sociedad) en cada persona; en cualquier caso, una persona se considerará vinculada a otra si, en función de todos los hechos y circunstancias relevantes, una tiene el control sobre la otra o ambas están bajo el control de la misma persona o personas; y (e) el término "beneficiario equivalente" significa cualquier persona que tendría derecho a un beneficio con respecto a una partida de renta concedido por un Estado Contratante en virtud de la legislación interna de ese Estado Contratante, el presente Convenio o cualquier otro acuerdo internacional que sea equivalente a, o más favorable que, el beneficio que se otorgará a esa partida de renta de conformidad con las disposiciones del párrafo 5 del Artículo 7 o del Artículo 10, 11, 12 o 13; para los efectos de determinar si una persona es un beneficiario equivalente con respecto a los dividendos recibidos por una sociedad, la persona se considerará como una sociedad y con el mismo poder de voto que tiene la sociedad que reclama el beneficio con respecto a los dividendos en la sociedad pagadora de los dividendos.

${ }^{49}$ El artículo 28 del CDI continúa diciendo: “7. (a) Cuando: (i) una empresa de un Estado Contratante obtenga rentas provenientes del otro Estado Contratante y el Estado Contratante mencionado en primer lugar considera tales rentas como atribuibles a un establecimiento permanente de la empresa situada en una tercera jurisdicción; y (ii) las utilidades atribuibles a ese establecimiento permanente están exentas de impuestos en el Estado Contratante mencionado en primer lugar, los beneficios en virtud del presente Convenio no se aplicarán a ninguna partida de renta a las cuales el impuesto en la tercera jurisdicción sea inferior al 60 por ciento del impuesto que se impondría en el Estado Contratante mencionado en primer lugar sobre esa partida de renta si ese establecimiento permanente estuviera situado en el Estado Contratante mencionado en primer

Revista de Derecho Fiscal n. ${ }^{\circ} 15$ • julio-diciembre de 2019 • pp. 59-91 
do fiscal fue lo que motivó la estructuración de la operación ${ }^{50}$.

\section{Misiones diplomáticas}

En lo que concierne a temas del régimen fiscal para miembros de las misiones diplomáticas o consulares de los respectivos países, el artículo 27 del CDI establece que los beneficios o privilegios fiscales que tengan estos primeros de acuerdo con los principios generales del Derecho internacional público o por disposiciones de acuerdos especiales, no se verán afectadas por el CDI.

Por lo tanto, las reglas especiales de tributación para miembros de estas misiones di- plomáticas contenidas en la Convención de Viena sobre Relaciones Consulares, suscrita el 24 de abril de $1963^{[51]}$ y la Convención de Viena sobre Relaciones Diplomáticas hecha en Viena el 18 de abril de $1961^{[52]}$, seguirán aplicando con normalidad dado que el CDI no tendrá impacto sobre ellas.

\section{Reglas especiales de interpretación}

Naturalmente, dado que los idiomas oficiales en Colombia y en Japón varían sustancialmente, siguiendo la norma de interpretación del artículo 33 de la Convención de Viena sobre el Derecho de los Tratados de $1969^{[53]}$, se estableció al final del CDI y

lugar. En tal caso, cualquier renta a la que se apliquen las disposiciones del presente párrafo seguirá sujeta a impuestos de conformidad con la legislación interna del otro Estado Contratante, sin perjuicio de cualquier otra disposición del Convenio. (b) Las disposiciones del subpárrafo (a) no se aplicarán si las rentas derivadas del otro Estado Contratante descrito en ese subpárrafo se derivan, están relacionadas con o son incidentales al desarrollo de un negocio empresarial activo realizada a través del establecimiento permanente (que no sea el negocio de hacer, administrar o simplemente mantener inversiones para el beneficio propio de la empresa, a menos que estas actividades sean actividades bancarias, de seguro o de valores llevadas a cabo por un banco, una empresa de seguros o un corredor de valores registrado, respectivamente). (c) Si los beneficios en virtud del Convenio son negados de conformidad con las disposiciones del subpárrafo (a) con respecto a una partida de renta obtenida por un residente de un Estado Contratante, la autoridad competente del otro Estado Contratante podrá, sin embargo, otorgar estos beneficios con respecto a esa partida de renta si, en respuesta a una solicitud de dicho residente, dicha autoridad competente determina que la concesión de tales beneficios está justificada a la luz de las razones por las cuales dicho residente no cumplió con los requisitos de los subpárrafos (a) y (b). La autoridad competente del Estado Contratante al que se haya hecho una solicitud en virtud de la frase anterior por un residente del otro Estado Contratante deberá consultar con la autoridad competente de ese otro Estado Contratante antes de otorgar o negar la solicitud".

${ }^{50}$ La última parte del artículo 28 del CDI señala: "8. Sin perjuicio de las demás disposiciones del presente Convenio, no se otorgará un beneficio en virtud del Convenio con respecto a una partida de renta si es razonable concluir, teniendo en cuenta todos los hechos y circunstancias pertinentes, que la obtención de ese beneficio fue uno de los principales propósitos de cualquier arreglo o transacción que resulte directa o indirectamente en ese beneficio, a menos que se establezca que otorgar ese beneficio en estas circunstancias estaría de acuerdo con el objeto y el propósito de las disposiciones pertinentes del Convenio".

${ }^{51}$ Aprobada en Colombia mediante la Ley 17 de 1971.

${ }^{52}$ Aprobada en Colombia mediante la Ley 6 de 1972.

${ }^{53}$ Dicho artículo señala: "Artículo 33. Interpretación de tratados autenticados en dos o más idiomas. 1. Cuando un tratado haya sido autenticado en dos o más idiomas, el texto hará igualmente fe en cada idioma, a menos que el tratado disponga o las partes convengan que en caso de discrepancia prevalecerá uno de los textos. 2. Una versión del tratado en idioma distinto de aquel en que haya sido autenticado el texto será considerada como texto auténtico únicamente si el tratado así lo dispone o las partes así lo convienen. 3. Se presumirá que los términos del tratado tienen en cada 
en el protocolo una disposición especial en virtud de la cual se indica que, en caso de divergencia de interpretación, prevalecerá en cualquier caso el texto en inglés.

Así, este acuerdo entre las partes antes señalado permite corregir cualquier conflicto interpretativo que puede nacer respecto de las disposiciones del tratado, en la medida en que se acordó que el CDI se expedía en tres idiomas, inglés, español y japonés, todos ellos auténticos, pero en donde siempre prevalecerá el que se encuentra en idioma inglés.

\section{Entrada en vigor}

En primera medida, el artículo 30 del CDI pone de presente que dicho acuerdo internacional entrará en vigor una vez se agoten los procedimientos internos para su adopción en ambas naciones, pero en todo caso a partir del mes siguiente al instrumento diplomático del canje notas.

Sin embargo, respecto del inicio de sus efectos, deberán tenerse presente lo que se presenta a continuación:

(a) en Colombia:

(i) con respecto a las retenciones en la fuente, a partir del 1 de enero del año calendario siguiente a aquél en que el CDI entre en vigor; $y$ (j) con respecto a todos los demás impuestos, después del 1 de enero del año calendario siguiente a aquél en que el Convenio entre en vigor; $y$,

(b) en Japón:

(i) con respecto a los impuestos recaudados sobre la base de un año fiscal, a partir del 1 de enero del año calendario siguiente a aquél en el cual el CDI entre en vigor; $y$

(j) con respecto a los impuestos que no sean recaudados sobre la base de un año fiscal, a partir del 1 de enero del año calendario siguiente a aquel en que el Convenio entre en vigor.

No obstante, las disposiciones de los artículos $25^{[54]}$ y $26^{[55]}$ tendrán efecto a partir de la fecha de entrada en vigor del CDI.

\section{Denuncia}

El artículo 31 del CDI señala que este acuerdo tributario estará vigente hasta tanto no haya sido denunciado por cualquiera de las partes mediante las vías diplomáticas respectivas; sin embargo, dicha notificación de denuncia deberá realizarse por lo menos seis meses antes de finalizar el año calendario siempre que hayan trascurrido tres años desde la fecha de entrada en vigor del CDI.

Como se observa, en cualquier caso, el CDI tendrá que tener vigor para las partes por

texto auténtico igual sentido. 4. Salvo en el caso en que prevalezca un texto determinado conforme a lo previsto en el párrafo 1. cuando la comparación de los textos auténticas revele una diferencia de sentido que no pueda resolverse con la aplicación de los artículos 31 y 39, se adoptará el sentido que mejor concilie esos textos, habida cuenta del objeto y fin del tratado".

${ }^{54}$ Artículo del CDI que versa sobre el intercambio de información.

${ }^{55}$ Artículo del CDI que versa sobre la asistencia en la recaudación de impuesto. 
al menos 3 años para que cualquiera de los Estados contratantes quede habilitado para denunciarlo. No obstante, para la cesación de efectos del CDI, también se deberán tener en consideración las siguientes reglas:

(a) en Colombia:

(i) con respecto a las tarifas de retención en la fuente estas no aplicarán a partir del final del año calendario en el que se dé la notificación de denuncia; y

(ii) con respecto a todos los demás impuestos, a partir del año calendario siguiente en que se da la notificación de denuncia; $y$

(b) en Japón:

(i) con respecto a los impuestos recaudados sobre la base de un año fiscal, a partir del 1 de enero del año calendario siguiente a aquél en que se da la notificación de denuncia; y

(ii) con respecto a los impuestos que no sean recaudados sobre la base de un año fiscal, a partir del 1 de enero del año calendario siguiente al que se da la notificación de denuncia.

\section{Conclusiones}

Es claro que la celebración del CDI con Japón es un peldaño más para Colombia en el cumplimiento de su meta de poseer una gran red de tratados tributarios, principalmente con sus socios económicos de mayor importancia. De esta manera, una vez se agoten los trámites internos de adopción y, por tanto, entre a regir el CDI, habrá un estímulo fiscal que fomente el intercambio entre Colombia y Japón.
Naturalmente, dado que el CDI fue firmado en diciembre de 2018, la mayor parte de su articulado está conforme a los nuevos estándares BEPS, que a su turno quedaron reproducidos en el MOCDE en su versión más actualizada de 2017.

Por lo tanto, consideramos que este CDI contiene disposiciones que a la postre lograrán evitar oportunidades de abusos del tratado, de treaty shopping o casos de doble no imposición. Lo anterior se ve reflejado en el CDI en un título que se refiere también a contrarrestar la evasión o elusión fiscal, una cláusula antiabuso con un híbrido de estándares PPT y LOB, un preámbulo más robusto, nuevos umbrales para actividades preparatorias y auxiliares en el criterio de $\mathrm{EP}$, entre otros.

Ahora bien, varias de las cosas negociadas en el CDI están en línea con las reservas hechas por Colombia al MOCDE, como, por ejemplo, permitir el gravamen en fuente de las regalías, permitir ejercer tributación en algunos eventos sobre las ganancias de capital por la venta de acciones, aprobar el gravamen en Colombia de las transferencias de un EP respecto de rentas no gravadas en el país, restringir la aplicación del CDI a tributos locales, entre otros.

Sin embargo, hay puntos en los cuales no hay congruencia respecto de la postura de Colombia al MOCDE, dado que, en el CDI, por ejemplo, no se consideró como regalía a los servicios técnicos, de asistencia técnica y consultoría o fijar alícuotas de retención en la fuente por dividendos menores que el $10 \%$. 


\section{Referencias}

Ley 7 de 1944.

Ley 17 de 1971.

Ley 6 de 1972.

Ley 32 de 1985.

Ley 1950 de 2019.

Constitución Política de Colombia.

Convención de Viena sobre el Derecho de los Tratados Internacionales de 1969.

Cabrera Cabrera, Omar (2016). El establecimiento permanente: especial énfasis en la Cláusula de agencia. Universidad Externado de Colombia.

Cabrera Cabrera, Omar (2018a). Modificaciones al objeto de los convenios tributarios comprendidos en el instrumento multilateral de la OCDE y sus incidencias para Colombia. Revista de impuestos $\mathrm{n}^{\circ} .209$.

Cabrera Cabrera, Omar (2018b). Tributación de los dividendos bajo el marco del instrumento multilateral de la OCDE y los efectos para Colombia. Revista de impuestos $\mathrm{n}^{\circ} .208$.

Cabrera Cabrera, Omar (2018c). El concepto de establecimiento permanente en el sistema tributario Colombia. Revista Instituto Colombiano de Derecho Tributario $\mathrm{n}^{\circ}$. 79. Diciembre de 2018.
Cabrera Cabrera, Omar (2018d). El descuento colombiano por impuestos pagados en el exterior: análisis teórico y práctico. Revista Instituto Colombiano de Derecho Tributario $\mathrm{n}^{\circ} .78$. Mayo de 2018.

Cabrera Cabrera, Omar (2018e). Principales cambios del Modelo de Convenio sobre la Renta y sobre el Patrimonio de la OCDE versión 2017. Revista de impuestos $\mathrm{n}^{\circ} .207$.

Cabrera Cabrera, Omar (2019). Tributación de las entidades con residencia dual en el instrumento multilateral de la OCDE y su repercusión para Colombia. Revista de impuestos $\mathrm{n}^{\circ} .211$.

Quiñones Cruz, Natalia (2012). Colombia Report, en Lang et al. (eds.) The Impact of the OECD and UN Model Conventions on Bilateral Tax Treaties. Cambridge Tax Law Series.

Mosquera Valderrama, Irma Johanna (2013). The International Tax Treaty Policy of Colombia. Bulletin for International Taxation, vol. 67, Issue n. 4-5. marzo 2013.

Fecha de recepción: 23 de julio de 2019

Fecha de aprobación par 1: 17 de agosto de 2019

Fecha de aprobación par 2: 15 de agosto de 2019 